\title{
Comparative insights into genome signatures of ferric iron oxide- and anode- stimulated Desulfuromonas spp. strains
}

\author{
Yong Guo, Tomo Aoyagi and Tomoyuki Hori
}

\begin{abstract}
Background: Halotolerant Fe (III) oxide reducers affiliated in the family Desulfuromonadaceae are ubiquitous and drive the carbon, nitrogen, sulfur and metal cycles in marine subsurface sediment. Due to their possible application in bioremediation and bioelectrochemical engineering, some of phylogenetically close Desulfuromonas spp. strains have been isolated through enrichment with crystalline Fe (III) oxide and anode. The strains isolated using electron acceptors with distinct redox potentials may have different abilities, for instance, of extracellular electron transport, surface recognition and colonization. The objective of this study was to identify the different genomic signatures between the crystalline Fe (III) oxide-stimulated strain AOP6 and the anode-stimulated strains WTL and DDH964 by comparative genome analysis.

Results: The AOP6 genome possessed the flagellar biosynthesis gene cluster, as well as diverse and abundant genes involved in chemotaxis sensory systems and c-type cytochromes capable of reduction of electron acceptors with low redox potentials. The WTL and DDH964 genomes lacked the flagellar biosynthesis cluster and exhibited a massive expansion of transposable gene elements that might mediate genome rearrangement, while they were deficient in some of the chemotaxis and cytochrome genes and included the genes for oxygen resistance.

Conclusions: Our results revealed the genomic signatures distinctive for the ferric iron oxide- and anode-stimulated Desulfuromonas spp. strains. These findings highlighted the different metabolic abilities, such as extracellular electron transfer and environmental stress resistance, of these phylogenetically close bacterial strains, casting light on genome evolution of the subsurface Fe (III) oxide reducers.
\end{abstract}

Keywords: Comparative genomics, Chemotaxis, Extracellular electron transport, c-type cytochrome, Flagellum, Cytochrome c oxidase, Transposable element, Desulfuromonas

\section{Background}

Microorganisms in earth's crust can change the redox state of extracellular metal oxides by transporting electrons from organic matter degradation [1-4]. These processes not only control the bioavailability of metal ions $[5,6]$ but also drive the global biogeochemical cycles [7, 8]. Due to the applicability in bioremediation and

* Correspondence: hori-tomo@aist.go.jp

Environmental Management Research Institute, National Institute of Advanced Industrial Science and Technology (AIST), 16-1 Onogawa, Tsukuba, Ibaraki 305-8569, Japan

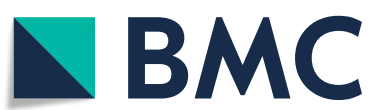

bioelectrochemical engineering, there have been a lot of efforts to obtain the culture collections of metalreducing bacteria from various natural environments, such as sediments and soils [9].

The order Desulfuromonadales contains abundant resources of metal oxide reducers, in which Geobacter sulfurreducens and its relatives affiliated with the family Geobacteriaceae have been well studied to reveal the molecular mechanisms underlying the direct electron transfer from microorganisms to crystalline metal oxides [10-16]. To date, it has been proved that some of the

(c) The Author(s). 2021 Open Access This article is licensed under a Creative Commons Attribution 4.0 International License, which permits use, sharing, adaptation, distribution and reproduction in any medium or format, as long as you give appropriate credit to the original author(s) and the source, provide a link to the Creative Commons licence, and indicate if changes were made. The images or other third party material in this article are included in the article's Creative Commons licence, unless indicated otherwise in a credit line to the material. If material is not included in the article's Creative Commons licence and your intended use is not permitted by statutory regulation or exceeds the permitted use, you will need to obtain permission directly from the copyright holder. To view a copy of this licence, visit http://creativecommons.org/licenses/by/4.0/ The Creative Commons Public Domain Dedication waiver (http://creativecommons.org/publicdomain/zero/1.0/) applies to the data made available in this article, unless otherwise stated in a credit line to the data. 
specific $c$-type cytochromes can establish a conductive pathway capable of crossing the inner membrane, periplasm and outer membrane that allows the Geobacter species to directly transport electrons from the quinone/ quinol pool to metal oxides [12,17]. Additionally, these bacteria produce the electrically conductive protein nanowires, i.e., the e-pili assembled from the PilA pilin monomer, to achieve long-range extracellular electron transport to metal oxide particles [16]. Compared to metal oxides serving as electron acceptor, constant voltage electrodes represent the unlimited electronaccepting potentials allowing microorganisms in contact with the inorganic surface to support the growth of the other distant ones, if these microorganisms can create a conductive network to relay electrons to the electrode [18]. A number of studies showed that some of metalreducing bacteria utilized the distinctive electron transfer proteins to access the electrodes. Chan and the colleagues constructed the genome-wise transposoninsertion sequencing libraries of G. sulfurreducens and found a new putative porin-cytochrome conduit complex (i.e., ext $A B C D$ ) crucial for growth with electrodes but not for Fe (III) oxide reduction [19]. Zacharoff et al. reported that deletion of the $p g c A$ gene, encoding an extracellular triheme $c$-type cytochrome, in the G. sulfurreducens genome generated the mutants unable to transfer electrons to the Fe (III) and Mn (IV) oxides but able to maintain the ability of electrode reduction [20]. These studies suggest that functional diversification of $c$-type cytochromes from G. sulfurreducens was responsible for electron transfer to a variety of extracellular electron acceptors, particularly the metal oxides and electrodes.

Cell mobility and extracellular structures (e.g., type-IV pili) are critical for the Geobacter physiology, when Geobacter spp. are grown with insoluble Fe (III) oxides [21]. The related metabolic processes could be potentially regulated by chemotaxis-like pathways. Various chemotaxis systems and chemo-receptors (e.g., methyl-accepting chemotaxis proteins [MCPs]) have been well characterized in the Geobacter genomes and probably play distinct roles in different cellular processes [22]. For example, it is suggested that the E. coli-like and Frz-like clusters participate in the flagellum-based and social motilities, respectively, while the Dif-like and Deltaproteobacteria-specific clusters regulate the synthesis of extracellular matrix materials, such as exopolysaccharides [22]. Moreover, the G. sulfurreducens mutants lacking components of a methylaccepting chemotaxis sensing network (i.e., esn $A B C D$ ) were defective in colonization on electrodes but grew normally with Fe (III) oxides, suggesting the distinct recognition and colonization mechanisms between the electrode and Fe (III) oxide reductions [19]. However, such detailed information on the other dissimilatory metal-reducing bacteria is still limited.
Apart from the Geobacteriaceae bacteria inhabiting in soils and freshwater ecosystems, the Desulfuromonadaceae members, including the genera Desulfuromonas, Pelobacter, Desulfuromusa, Malomonas and Geoalkalibacter, are mainly isolated from marine sediments [2326], tidal flat [27], petroleum reservoir [28], other subsurface and/or saline ecosystems [29-31]. Desulfuromonas species can catalyze oxidation of a wide range of organic compounds coupled with dissimilatory reduction of metal oxides, elemental sulfur and polysulfide $[2,30$, 32]. Due to their high tolerance to saline stress, Desulfuromonas spp. have attracted attention for applicability in the saline wastewater treatment [33].

Until recent years, a few of the pure and enrichment cultures of the genus Desulfuromonas have been established with different stimulation approaches. 'Desulfuromonas soudanensis' WTL and Desulfuromonas sp. DDH964 were cultured from the underground Soudan iron mine through in situ enrichment with the graphite anode at $+0.24 \mathrm{~V}$ (vs the standard hydrogen electrode [SHE]) as electron acceptor [29]. The two strains formed a separate clade together with Desulfuromonas sp. TF that was isolated with an electrode as the acceptor [29]. The anode-stimulated strain WTL released electrons at approximately $0.1 \mathrm{~V}$ more positive redox potentials compared to G. sulfurreducens, while it showed slower Fe (II) generation rates when incubated with a poorly crystalline Fe (III) oxide, revealing that its extracellular respiration is tuned for high-potential electron acceptors [29]. The strain WTL survived under the unplanned oxygen exposures, due to power outage in laboratory [29], suggesting the oxygen tolerance ability of this strain. On the other hand, Desulfuromonas sp. AOP6 was anaerobically isolated from the subseafloor sediments through enrichment with the crystalline Fe (III) oxide goethite $(\alpha-\mathrm{FeOOH})$ as electron acceptor in our previous studies [34, 35]. The redox potentials of the crystalline Fe (III) oxides (less than $-0.1 \mathrm{~V}$ vs SHE) [36] were lower than that of the constant electrode used to isolate the strain WTL $(+0.24 \mathrm{~V}$ vs SHE) [29], suggesting that the crystalline Fe (III) oxide-stimulated strain could use low-potential electron acceptors. In addition, another strict anaerobic strain, Desulfuromonas acetexigens $2873^{\mathrm{T}}$, was originally isolated from the digester sludge using acetate and elemental sulfur as the electron donor and acceptor, respectively, corresponding to the redox potential of $-0.24 \mathrm{~V}$ vs SHE [32, 37]. This sulfurstimulated strain possesses a single flagellum in polar and can respire the elemental sulfur [32], as well as transport electron to the anode [38], while its ability of reducing the Fe (III) oxides has not been examined. These Desulfuromonas spp. strains obtained using electron acceptors with distinct redox potentials show different physiological properties and thus they may have 
distinct gene features, for instance, on extracellular electron transport, chemotaxis systems and oxygen tolerance. However, the functional traits and relationships of these phylogenetically close bacterial strains have not been studied well.

The objectives of this study were (i) to determine the genome-wise phylogenetic relationship of all the available genomes from the representative isolates in the order Desulfuromonadales (i.e., the higher taxon of the family Desulfuromonadaceae) and (ii) to perform comparative genome analysis to identify the different genomic signatures of the phylogenetically close Desulfuromonas spp. strains AOP6, WTL and DDH964 that were isolated using the different electron accepters, i.e., crystalline ferric iron oxide and anode.

\section{Results \& discussion}

Phylogenomic position of halotolerant Fe (III) oxidereducing bacteria in the family Desulfuromonadaceae

A genome-wide phylogenetic analysis of the order Desulfuromonadales was performed using concatenated amino acid sequences of 371 conserved proteins from 50 Desulfuromonadales genomes. The maximum-likelihood phylogenetic tree showed that these genomes were clearly grouped into two clades (Fig. 1). One clade consisted of the genera within the family Desulfuromonadaceae, i.e., Desulfulomoas, Pelobacter, Geoalkalibacter, Desulfuromusa and Malonomonas, and the two Geobacteriaceae-related genera Geothermobacter and Geopsychrobacter [39], which is defined as the Desulfuromonadaceae clade. The other contained the genera within the family Geobacteraceae, i.e., Geobacter, two recently-described Geomonas [40] and Oryzomonas [41], and a single species of Pelobacter propionicus, which is defined as the Geobacteraceae clade. The recently discovered crystalline Fe (III) oxide reducer Desulfuromonas sp. AOP6 [34, 35] was placed on the deepest branch of the Desulfuromonadaceae clade and formed a cluster together with the sulfur-reducing Desulfuromonas acetexigens $2873^{\mathrm{T}}$ [32, 38]. The electroderespiring bacteria 'Desulfuromonas soudanensis WTL' [29], Desulfuromonas sp. DDH964 (or named as 'Ca. Desulfuromonas biiwaabikowi DDH964' [29]) and Desulfuromonas sp. TF [27] were phylogenetically close to each other and formed a cluster neighbor to the AOP6 cluster. These two clusters formed a subclade neighbor to the genus Geoalkalibacter.

Despite the phylogenetically close relationship of these Fe (III) oxide-, sulfur- and anode-stimulated bacterial strains AOP6, 2873 ${ }^{\mathrm{T}}$, WTL, DDH964 and TF, their genome sizes (3.26 to $4.40 \mathrm{Mb}$ ) and $\mathrm{G}+\mathrm{C}$ contents (56.4 to $62.2 \%$ ) were different to some extent (Table 1 ). Such differences appeared to be associated with the transposon expansion but not plasmid expansion in the genome. Neither plasmid-like sequence nor plasmid replication gene was found in the genomes of the 5 strains. In addition, the pairwise average nucleotide identities (ANI) among the 5 genomes were in a range from 69.9 to $72.5 \%$ (Table 2), being lower than the reported ANI cutoff values of the same species (94 95\%) [42]. Meanwhile, the pairwise average amino acid identities (AAI) of them ranging from 62.7 to $66.5 \%$ (Table 2) were lower than the threshold value (i.e., $70 \%$ ) to define the recently described genera Geomonas and Oryzomonas in the family Geobacteraceae $[40,41]$. These results suggested that some of these Desulfuromonas spp. strains would represent the new species in the family Desulfuromonadaceae.

\section{General comparison of crystalline Fe (III) oxide- and} anode-stimulated Desulfuromonas spp. strains

A phylogenetic orthology analysis using OrthoFinder [43] was performed to compare the genomes of the 5 Desulfuromonas spp. strains. Overall, 14,437 of the total 17,479 genes from the compared 5 genomes, accounting for $82.6 \%$ of the total genes, were assigned into 3423 orthologous groups (OGs) (Fig. 2). Hierarchical clustering analysis of the OGs revealed the different patterns of gene contents among the Fe (III) oxide-, sulfur-, and anode-stimulated strains (Fig. 2A). Among these OGs, 1515 OGs were identified as the core OGs, ranging from 42.1 to $54.8 \%$ of the total genetic elements of each strain (Fig. 2B). In addition, 190 and 132 OGs were shared only by the strains isolated using the inorganic electron acceptors (i.e., ferric iron oxide or sulfur) and anode, respectively (Fig. 2B). These results underscored a large genetic difference of these phylogenetically close bacterial strains.

Syntenic comparisons of the complete genome sequence of the Fe (III) oxide-stimulated strain AOP6 with those of the anode-stimulated strains WTL (Fig. 3A) and DDH964 (Fig. 3B) were performed to determine the genomic difference and rearrangement between the Desulfuromonas spp. strains stimulated with different electron acceptors. From the comparisons, the Fe (III) oxidestimulated strain AOP6 was characterized by the presence of a complete gene cluster for flagellar biosynthesis in the genome (Fig. 3). Interestingly, this gene cluster was highly conserved in the genomes of Desulfuromonadales bacteria except for 4 strains of the anodestimulated Desulfuromonadaceae bacteria (i.e., 'D. soudanensis' WTL, Desulfuromonas sp. DDH964, Desulfuromonas sp. TF, and Geopsychrobacter electrodiphilus DSM 16401) (Fig. 1). Previous studies revealed that Geobacter species expressed flagella for chemotaxis toward Fe (III) oxides in subsurface environments to achieve the efficient respiration [21, 44]. The conservation of the flagellar biosynthetic gene cluster by the Desulfuromonadales members may have reflected their long-term association with the $\mathrm{Fe}$ (III)-oxide respiration, because 


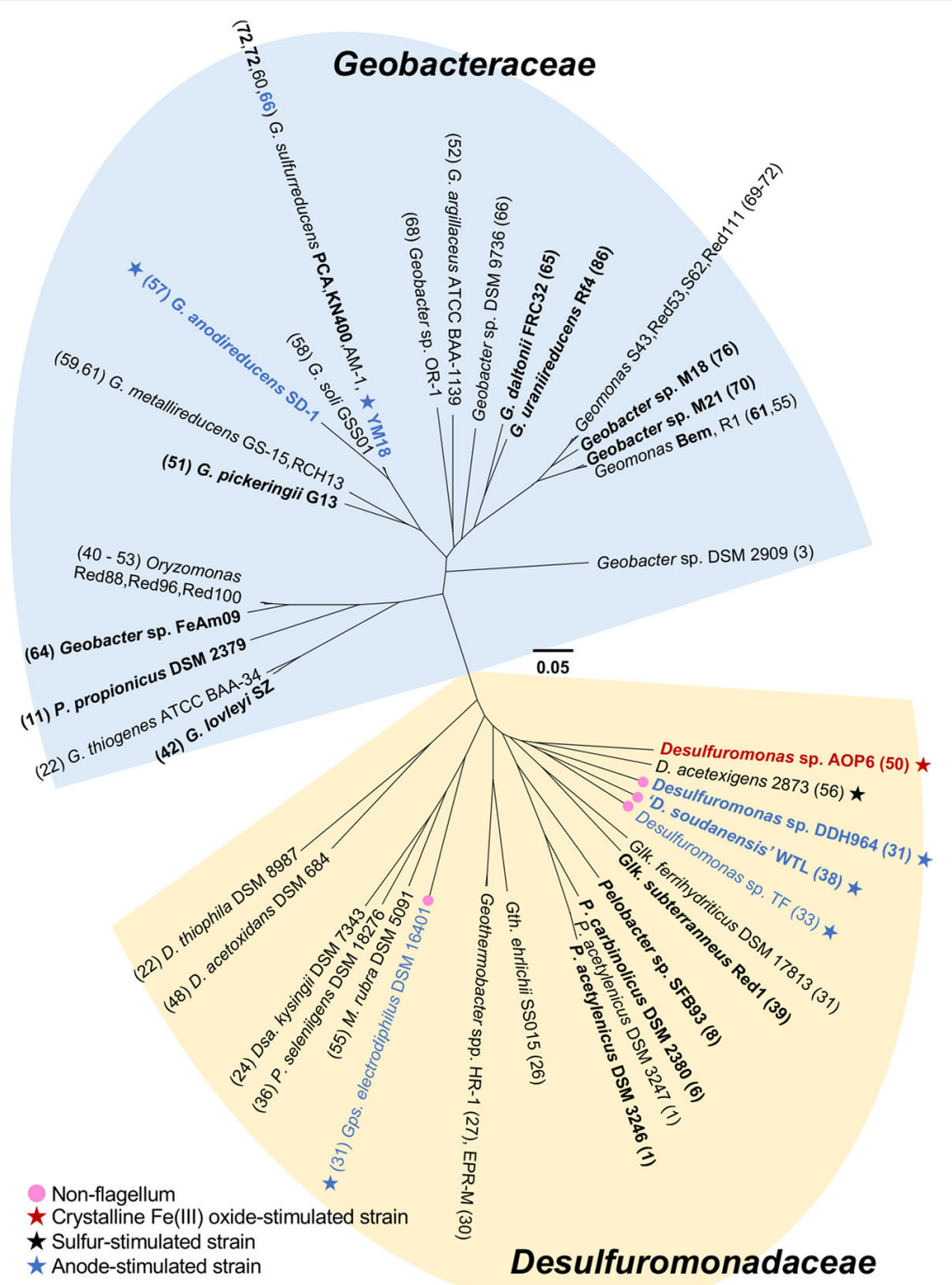

Fig. 1 Phylogenomic position of the 5 Desulfuromonas spp. strains in the reconstructed maximum likelihood (ML) tree based on the concatenated amino acid sequences deduced from 371 single-copy housekeeping genes. The branch length shows genetic distance with 1000 bootstrap replicates. Blue color font shows the anode-stimulated strains in the order Desulfuromonadales. Bold and normal fonts show the complete and incomplete genome sequences, respectively, of the strains. Number in brackets shows the count of deduced multiheme c-type cytochrome in the genomes. Pink circle shows the strain that had no gene cluster for flagellum biosynthesis, and the red, black and blue stars show the strains stimulated by using the crystalline Fe (III) oxide, elemental sulfur and anode as the electron acceptors, respectively

Table 1 Desulfuromonas genomes used for comparative genomics

\begin{tabular}{|c|c|c|c|c|c|c|c|c|c|}
\hline Name & $\begin{array}{l}\text { Isolation } \\
\text { approach }\end{array}$ & $\begin{array}{l}\text { Sample } \\
\text { type }\end{array}$ & $\begin{array}{l}\text { Assembly } \\
\text { level }\end{array}$ & GC\% & $\begin{array}{l}\text { Size } \\
{[\mathrm{bp}]}\end{array}$ & CDS & Transposase & Reference & Accession \\
\hline $\begin{array}{l}\text { Desulfuromonas sp. } \\
\text { AOP6 }\end{array}$ & $\begin{array}{l}\text { Geothite } \\
\text { stimulated }\end{array}$ & Cell culture & Complete & 56.4 & $3,269,909$ & 3000 & 10 & Guo et al. 2020 & AP022810 \\
\hline D. acetexigens $2873^{\top}$ & $\begin{array}{l}\text { Sulfur } \\
\text { stimulated }\end{array}$ & Cell culture & Contig & 60.3 & $3,683,125$ & 3388 & 31 & Katuri et al. 2017 & GCF_900111775 \\
\hline 'D. soudanensis WTL' & $\begin{array}{l}\text { Anode } \\
\text { stimulated }\end{array}$ & Cell culture & Complete & 61.2 & $3,958,620$ & 3504 & 78 & Badalamenti et al. 2016 & CP010802 \\
\hline $\begin{array}{l}\text { Desulfuromonas sp. } \\
\text { DDH964 }\end{array}$ & $\begin{array}{l}\text { Anode } \\
\text { stimulated }\end{array}$ & Enrichment & Complete & 62.2 & $3,924,652$ & 3574 & 111 & $\begin{array}{l}\text { Badalamenti, JP } \\
\text { (unpublished) }\end{array}$ & СР015080 \\
\hline $\begin{array}{l}\text { Desulfuromonas sp. } \\
\text { TF }\end{array}$ & $\begin{array}{l}\text { Electrode } \\
\text { stimulated }\end{array}$ & Enrichment & Scaffold & 58.6 & $4,402,753$ & 4013 & 6 & Kim et al. 2014 & GCF_000472285 \\
\hline
\end{tabular}


Table 2 Pairwise similarities (\%) of ANI and AAl among the five Desulfuromonas genomes

\begin{tabular}{lllllll}
\hline & & ANI & & & & \\
\cline { 3 - 7 } & & AOP6 & $\mathbf{2 8 7 3}^{\text {T }}$ & WTL & DDH964 & TF \\
\hline AAI & AOP6 & $*$ & 70.4 & 70.6 & 70.1 & 69.9 \\
& $2873^{\top}$ & 63.5 & $*$ & 72.2 & 71.6 & 71.0 \\
WTL & 64.7 & 63.8 & $*$ & 72.3 & 72.5 \\
& DDH964 & 63.3 & 62.8 & 65.3 & $*$ & 71.0 \\
TF & 63.9 & 62.7 & 66.5 & 64.7 & $*$ \\
\hline
\end{tabular}

Fe (III) has been thought to be abundant on the primitive Earth, potentially serving as the globally significant extracellular electron acceptor, even prior to the availability of nitrate, sulfate, and oxygen [45]. However, in the possible evolutionary history of G. sulfurreducens, a transposase gene was inserted into the master transcriptional regulator for the flagellar gene expression, which disrupted the flagella expression and further impaired the Fe (III) oxide reduction [44]. Therefore, we hypothesized that the lack of the flagellar biosynthetic gene cluster would trigger or enhance the Fe (III) oxidereducing bacteria to alter the way to transfer electrons, e.g., to use alternative electron acceptors. Our comparative analysis showed that the AOP6 genome contained more chemotaxis gene clusters and specific multiheme $c$-type cytochrome encoding genes, whereas the WTL and DDH964 genomes possessed the operons for the $\mathrm{Caa}_{3^{-}}$and $c b b_{3}$-type cytochrome $c$ oxidases, more abundant transposable elements (TEs), and more abundant pseudogenes. Additionally, a number of genomic rearrangements identified from the comparisons (the strain AOP6 vs WTL or DDH964) were widely distributed across the whole genomes (Fig. 3). The genomic

(A)

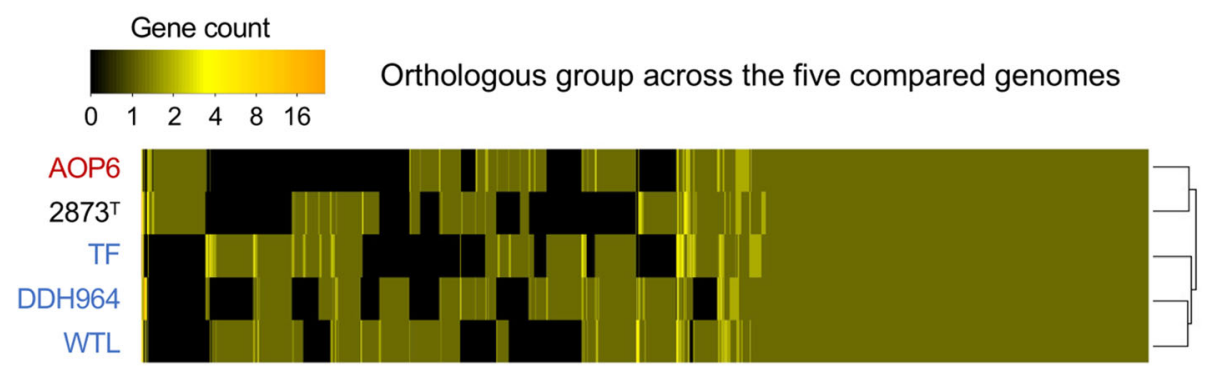

(B)
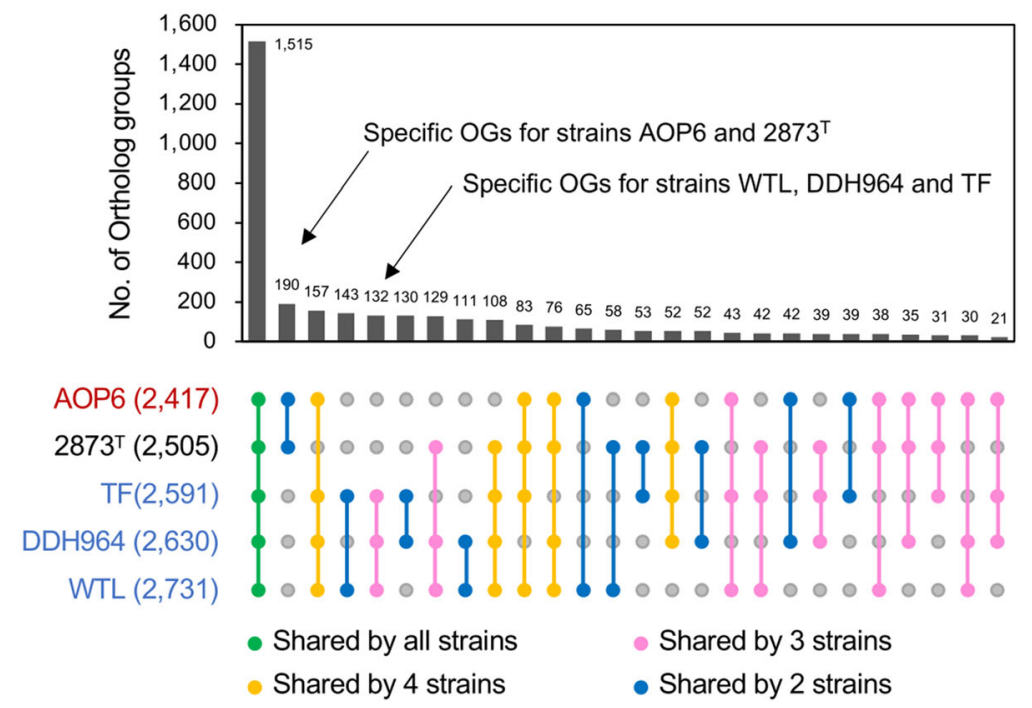

Fig. 2 Orthologous groups (OGs) across the genomes of the 5 Desulfuromonas spp. strains. A, heatmap with hierarchical clustering showing the OGs patterns of the 5 strains. B, bar plot showing the counts of OGs shared by the different strains. Red-, black-and blue-colored strain names in A and B show those strains stimulated by using the crystalline Fe (III) oxide, elemental sulfur and anode as the electron acceptors, respectively. Number above each bar in B shows the count of OGs shared by the strains. Number in brackets in B shows the count of OGs deduced in the genome of each strain. The colored dots with links in B show the orthologous groups shared by all the 5 strains (green), 4 of the strains (yellow), 3 of the strains (pink), and 2 of the strains (blue) 


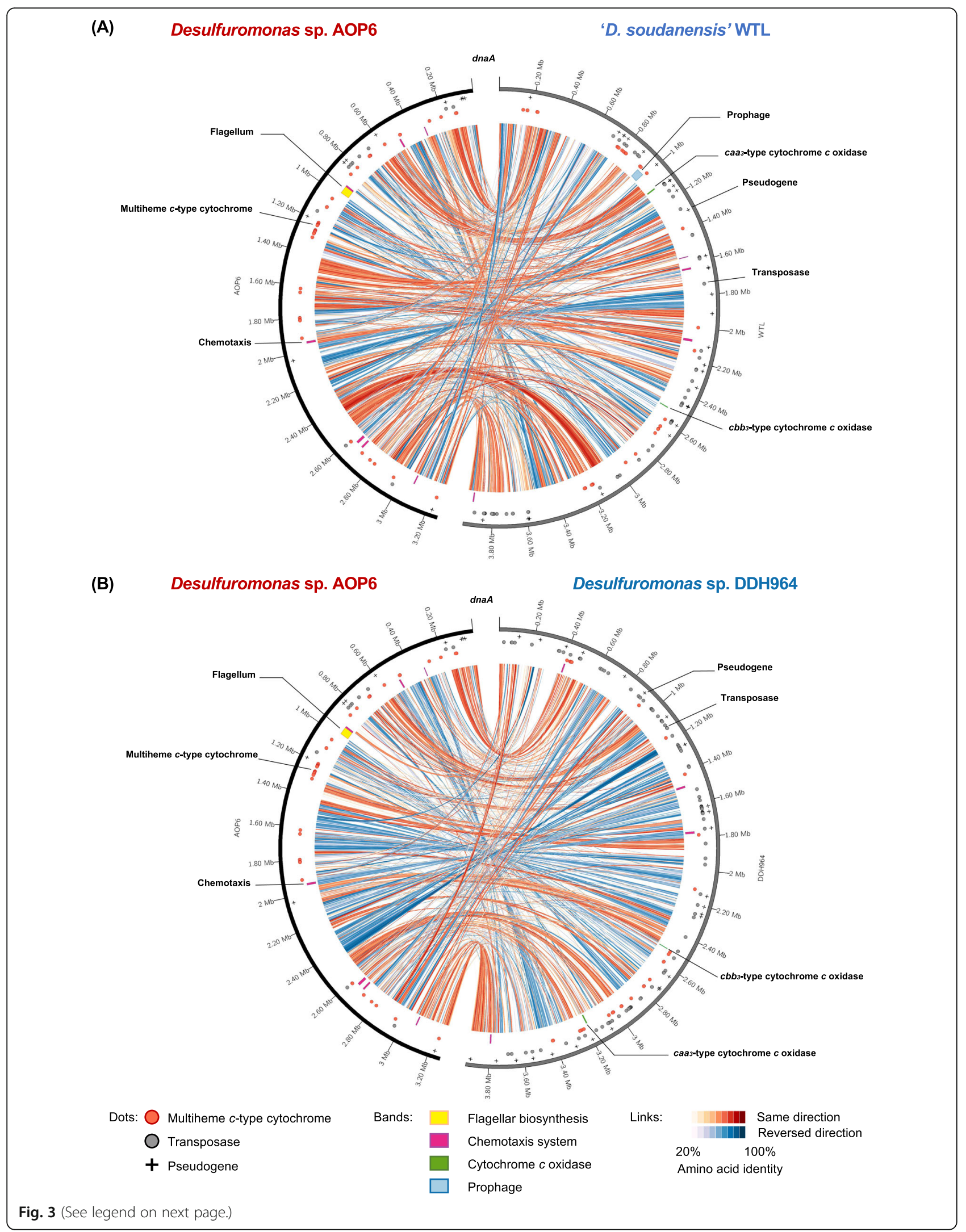


(See figure on previous page.)

Fig. 3 Syntenic comparative genomic analysis data using the complete genome sequences of the strains AOP6, WTL and DDH964. A, the strain AOP6 versus WTL. B, the strain AOP6 versus DDH964. Red- and blue-colored strain names in A and B show those strains stimulated by using the crystalline Fe (III) oxide and anode as the electron acceptors, respectively. Symbols next to the scale show the positions of pseudogenes (black crosses), as well as those of the genes responsible for the biosyntheses of the multiheme $c$-type cytochromes (red dots) and transponsases (grey dots), while bands next to the links show the positions of gene clusters responsible for the biosyntheses of the flagellum (yellow), chemotaxis system (magenta) and cytochrome c oxidase (green), as well as that of the prophage (sky blue). Links associated with the two genomes show homologous genes in same (red) and reverse (blue) directions. The gradient color of the link shows the identity between the amino acid sequences deduced for the homologous genes

rearrangement likely affected the gene expression and induced the loss of gene function when a breakpoint occurred inside a reading frame [46, 47]. Actually, 34 and 27 pseudogenes predicted in the genomes of the anodestimulated strains WTL and DDH964 were identified by frameshifting and missing the $\mathrm{N}$ - and/or C-terminus (data not shown). Taken together, these differences highlighted the functional diversification of the dissimilatory reduction processes catalyzed by the ferric iron oxide- and anode-stimulated Desulfuromonas spp. strains.

\section{Chemotaxis system}

Multiple copies of the chemotaxis genes were identified in the 5 genomes by using Microbial Signal Transduction Database (MiST) 3.0 [48]. Despite relatively small sizes of these genomes, 61 and 64 homologs to the che and $m c p$ genes were found in the strains AOP6 and $2873^{\mathrm{T}}$ genomes, respectively, whereas the strains WTL, DDH964 and TF possessed 48 to 56 of these genes (Table 3). Most of the che genes were clustered in the genomes of the 5 strains (Fig. 4), except for the genes for chemoreceptors of the MCPs that were dispersed throughout the genomes (data not shown). The organization pattern of chemotaxis genes was consistent with those found in the genomes of Geobacter species [22]. There were 7, 6, 4, 4 and 5 major chemotaxis gene clusters in the AOP6, 2873 ${ }^{\mathrm{T}}$, WTL, DDH964 and TF genome, respectively. Their physical arrangements are showed in Fig. 4. In the case of the strains AOP6 and $2873^{\mathrm{T}}$, the chemotaxis gene clusters (locus tags: AOP6 0888-0878 and BQ4888_RS06735-06680) were located on the upstream of the flagellar biosynthesis gene clusters (AOP6_0942-0890 and BQ4888_RS06745-06865).

Three to 6 of the cheA and cheAY genes, encoding the autophosphorylating histidine kinase (CheA), were predicted to be on the 5 genomes (Table 3), while these were homologous to the known cheA genes in the Geobacter species. Previously, Tran and the colleagues reported that the multiple cheA genes in the Geobacter species were the paralogous genes that evolved separately, whereas each of cheA gene together with other che genes likely regulated a separate chemotaxis pathway [22]. Moreover, 10 to 21 of the cheY genes, encoding response regulators as the substrates of CheA-mediated phosphorylation in chemotaxis pathways, were predicted to be on the 5 genomes. But only 6 to 11 of these genes were arranged in the chemotaxis gene clusters, being probably involved in chemotaxis signaling [49]. Meanwhile, the remainder che $Y$ genes were located on the chromosome, thus some of them seemed to function in the two-component pathways unrelated to chemotaxis [22]. These two-component pathway-related che $Y$ genes were detected only in the genomes of the strains AOP6 and $2873^{\mathrm{T}}$.

A number of genes for MCPs were found in the 5 genomes; 14 in the strain AOP6, 18 in $2873^{\mathrm{T}}, 15$ in WTL, 10 in DDH964, and 7 in TF (Table 3). MCPs have been assigned to different classes that designated $24 \mathrm{H}, 28 \mathrm{H}$,

Table 3 Gene counts of chemotaxis homologs in the five Desulfuromonas genomes

\begin{tabular}{|c|c|c|c|c|c|c|}
\hline & & \multicolumn{5}{|c|}{ Desulfuromonas } \\
\hline & & AOP6 & $2873^{\top}$ & WTL & DDH964 & TF \\
\hline \multicolumn{2}{|l|}{ cheA } & 4 & 5 & 3 & 4 & 3 \\
\hline \multicolumn{2}{|l|}{ cheAY ${ }^{a}$} & 1 & 1 & 0 & 0 & 0 \\
\hline \multicolumn{2}{|l|}{ cheB } & 3 & 3 & 4 & 4 & 6 \\
\hline \multicolumn{2}{|l|}{ cher } & 3 & 5 & 3 & 4 & 6 \\
\hline \multicolumn{2}{|l|}{ chew } & 6 & 8 & 9 & 6 & 8 \\
\hline \multicolumn{2}{|l|}{ chex ${ }^{a}$} & 3 & 3 & 0 & 0 & 0 \\
\hline \multicolumn{2}{|l|}{$c h e y^{b}$} & $15(11)$ & $16(10)$ & $17(8)$ & $10(6)$ & $21(8)$ \\
\hline \multicolumn{2}{|l|}{ chec } & 2 & 2 & 1 & 1 & 2 \\
\hline \multicolumn{2}{|l|}{ cheD } & 3 & 2 & 2 & 2 & 2 \\
\hline \multicolumn{2}{|l|}{ chev } & 0 & 1 & 0 & 0 & 1 \\
\hline \multirow[t]{6}{*}{$m c p$} & Total & 14 & 18 & 15 & 10 & 7 \\
\hline & $34 \mathrm{H}$ & 2 & 3 & 8 & 2 & 1 \\
\hline & $36 \mathrm{H}$ & 5 & 7 & 0 & 0 & 0 \\
\hline & $40 \mathrm{H}$ & 2 & 2 & 1 & 3 & 1 \\
\hline & $44 \mathrm{H}$ & 4 & 5 & 4 & 2 & 3 \\
\hline & $64 \mathrm{H}$ & 1 & 1 & 2 & 3 & 2 \\
\hline \multicolumn{2}{|l|}{ Total ${ }^{c}$} & $61(46)$ & $64(40)$ & $54(27)$ & $48(29)$ & $56(29)$ \\
\hline \multicolumn{2}{|l|}{ che cluster } & 7 & 6 & 4 & 4 & 5 \\
\hline
\end{tabular}

${ }^{a}$ The specific che genes possessed by the flagellum-harboring strains AOP6 and $2873^{\top}$

${ }^{b}$ The numbers in brackets indicate the counts of cheY genes in the major clusters shown in Fig. 4

'The numbers in brackets indicate the counts of chemotaxis genes in the major clusters shown in Fig. 4 


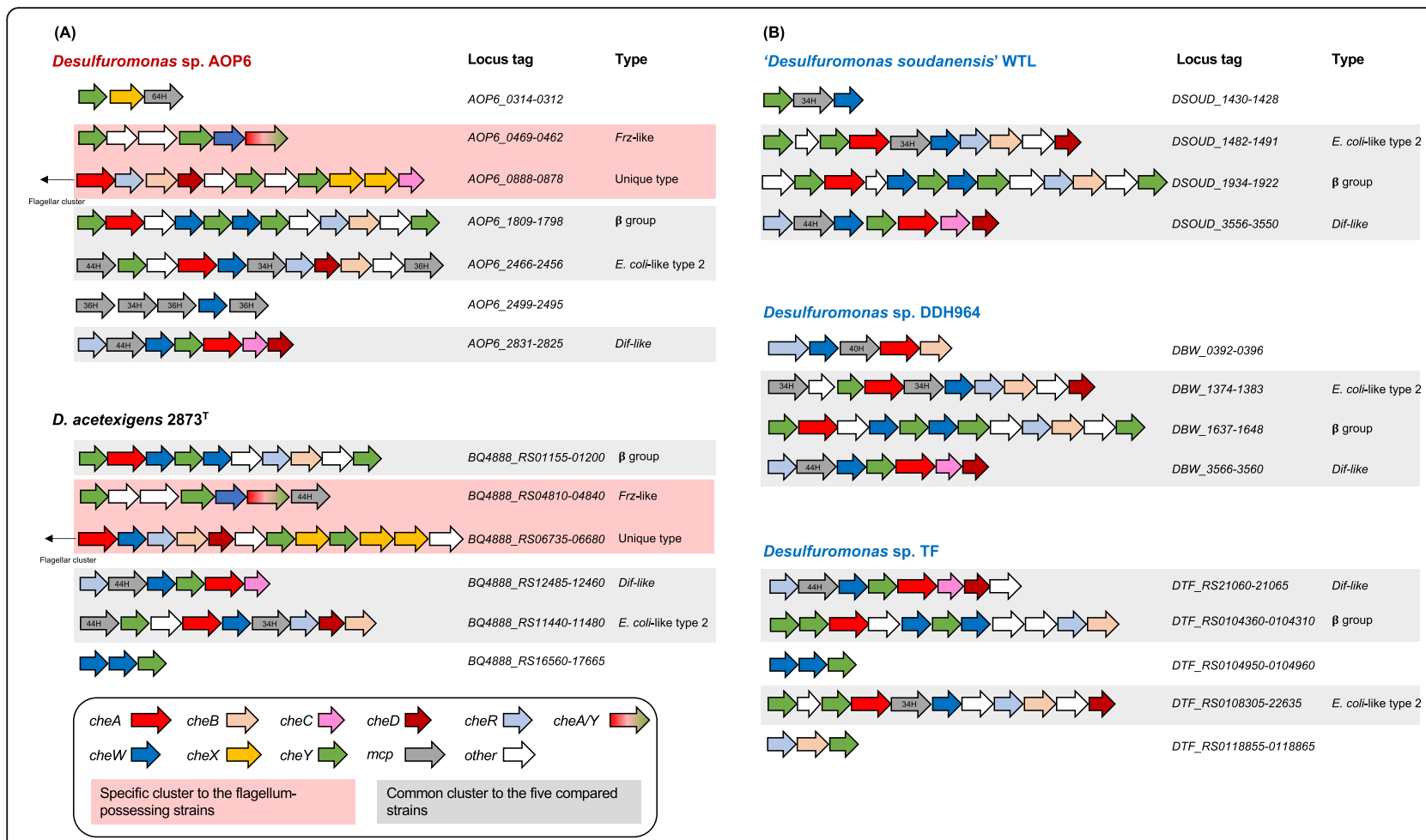

Fig. 4 Physical arrangements of the chemotaxis gene clusters in the complete genomes of the 5 strains. A, the gene clusters possessed by the crystalline Fe (III) oxide- and sulfur-stimulated strains; B, the gene clusters possessed by the anode-stimulated strains. Red- and black-colored strain names in A as well as the blue-colored strain names in B show those strains stimulated by using the crystalline Fe (III) oxide, sulfur and anode as the electron acceptors, respectively. Different colors show the chemotaxis genes of cheA (red) coding for an autophosphorylating histidine kinase, cheB (champagne) for a methylesterase, cheC (pink) for a protein phosphatase, cheD (maroon) for a chemoreceptor glutamine deamidase, cheR (baby blue) for a methyltransferase, cheW (blue) for a scaffold protein, cheX (yellow) for a dimer-form protein phosphatase, chey (green) for a response regulator, and cheAY (a gradient from red to green) for a CheA-CheY fusion protein, as well as mcp (grey) coding for a methylaccepting chemotaxis protein and other genes (white). Locus tags and types of chemotaxis clusters are listed next to the diagrams. The types of chemotaxis clusters are identified by comparing with the well-known 6 types of chemotaxis clusters conserved in the genomes of Geobacter sulfurreducens, Geobacter metallireducens and Geobacter uraniireducens. E. coli-like type 2 contains the non-chemotaxis genes and multiple mcp genes in the cluster. Frz-like type contains the cheAY fusion genes in the cluster. Dif-like type contains the genes of $44 \mathrm{H}-m c p, c h e A$, cheC, cheD, cheW and cheY in the cluster. Deltaproteobacteria-specific $\beta$ group clusters contain the genes of cheA, cheB, cheR and cheW, but no mcp genes. Red-colored background of the gene clusters indicates the specific clusters to the flagellum-possessing strains AOP6 and $2873^{\top}$, while greycolored background indicates the common clusters to the 5 strains

$34 \mathrm{H}, 36 \mathrm{H}, 38 \mathrm{H}, 40 \mathrm{H}, 44 \mathrm{H}$ and $64 \mathrm{H}$ according to the number of 7 -aa heptad repeats $(\mathrm{H})$ in the cytoplasmic domain [50]. Among them, the MCPs of the classes $36 \mathrm{H}$ and $44 \mathrm{H}$ were well characterized in Escherichia coli and Bacillus subtilis, respectively. In the class of $36 \mathrm{H}$ receptors of $E$. coli, the positive stimuli increased methylation at all the responsible sites and further decreased kinase activity, whereas the class $44 \mathrm{H}$ receptor of B. subtilis had a different methylation mechanism, in which only one site was methylated and the other sites were demethylated in response to the positive stimuli, resulting in the increase in kinase activity [51]. Multiple alignments of the predicted MCPs showed that the strains AOP6 and $2873^{\mathrm{T}}$ had MCPs of the classes $34 \mathrm{H}, 36 \mathrm{H}, 40 \mathrm{H}, 44 \mathrm{H}$ and $64 \mathrm{H}$, and the strains WTL, DDH964 and TF had those of the classes $34 \mathrm{H}, 40 \mathrm{H}, 44 \mathrm{H}$ and $64 \mathrm{H}$. Although the anode-stimulated strains lacked the MCPs of the class
$36 \mathrm{H}$ that were previously detected in the genomes of Geobacter metallireducens and G. uraniireducens [22], all of these 5 strains possessed the homologs of the $40 \mathrm{H}$ MCP EsnA that was probably associated with the colonization on electrodes [19].

Six types of the chemotaxis clusters in the G. sulfurreducens, G. metallireducens and G. uraniireducens genomes were well characterized [22]. Here, the types of chemotaxis clusters found in the 5 genomes were predicted by comparison with the above-mentioned 6 types. The E. coli-like cluster type 2, Dif-like and Deltaproteobacteria-specific $\beta$ group clusters were found in all the genomes (Fig. 4); whereas the Frz-like clusters were detected in the AOP6 and $2873^{\mathrm{T}}$ genomes (Fig. 4). Though the chemotaxis clusters AOP6_0888-0878 and BQ4888_ RS06735-06680 in the upstream of the flagellar clusters were similar to the $\beta$ group clusters containing the 
chemotaxis genes (i.e., che $A$, cheW, cheB and cheR) but no $m c p$ genes, this cluster also included other chemotaxis genes (i.e., che $C$, che $D$ and cheX), indicating a unique type of chemotaxis cluster for the strains AOP6 and $2873^{\mathrm{T}}$ (Fig. 4A). The cheC and cheD genes, encoding the phosphatases of CheY protein (CheY-P) and the chemoreceptor glutamine deamidases, respectively, were translationally coupled and interacted to each other to regulate the chemotaxis sensing, whereas the cheX gene encoded another type of CheY-P phosphatase, i.e., CheX, that was different from the CheC [52]. Two monomers of CheX formed a homodimer as a functional unit that represented the most powerfulness CheC-type phosphatase $[52,53]$. Due to the physically position neighbor to the flagellar clusters, it was tempting to speculate that these clusters (AOP6_0888-0878 and BQ4888_ RS06735-06680) regulated the flagellar-based motility of the strains AOP6 and $2873^{\mathrm{T}}$. However, as the complexity of gene organization, the functional details of this cluster should be further examined by molecular approaches. Overall, compared with the anode-stimulated Desulfuromonas spp. strains, the Fe (III) oxide- and sulfurstimulated strains AOP6 and $2873^{\mathrm{T}}$ possessed more abundant and diverse chemotaxis genes, in addition to the complete flagellar biosynthesis gene cluster, thereby enabling their possibly versatile cellular behaviors in response to environmental stimuli.

\section{Multiheme c-type cytochrome}

Multiheme $c$-type cytochromes are key for electron transport during the metal oxide and electrode respirations. To assess the diversity of the cytochromes, 28, 27, 24, 19 and 22 orthologous groups of multiheme $c$-type cytochromes (OGCs) were picked up from the genomes of the strains AOP6, 2873 ${ }^{\mathrm{T}}$, WTL, DDH964 and TF, respectively (43
OGCs in total). A heatmap with hierarchical clustering of these OGCs showed that the profiles of multiheme $c$-type cytochrome of the 5 strains were clearly grouped into two clusters; one consisted of the strains AOP6 and $2873^{\mathrm{T}}$, while the other was comprised of the strains WTL, DDH964 and TF (Fig. 5). There were only 5 core OGCs possessed by all the five strains, i.e., the homologous genes of omcI (OGC02), ppcA (OGC03), omcQ (OGC04), imcH (OGC14) and $c b c L$ (OGC15) characterized in the Geobacter species [10, 54]. ImcH and $\mathrm{CbcL}$ were identified as the inner membrane $c$-type cytochromes involved in the early steps of electron transfer to extracellular substrates in $G$. sulfurreducens, and further the two cytochromes would be required for reduction of electron acceptors with different redox potentials [55]. ImcH was for the acceptors with redox potentials higher than $0.1 \mathrm{~V}$ vs SHE, such as Fe (III) citrate and insoluble Mn (IV) oxides [56], while CbcL was for the low redox potential acceptors, such as the crystalline Fe (III) oxide goethite [57]. PpcA, a periplasmic $c$-type cytochrome, was employed in reduction of Fe (III) citrate [58], but not insoluble Fe (III) oxides and electrodes [59]. OmcI, an outer membrane $c$-type cytochrome, appeared to participate in reduction of Fe (III) oxide [59], while another one, i.e., $\mathrm{OmcQ}$, was likely irrelevant to reduction of Fe (III) oxide [60], despite the fact that the OmcQ expression significantly increased when cultivated under a low electrode potential of $-0.25 \mathrm{~V}$ vs SHE [61]. Although the 5 core OGCs of the $c$-type cytochrome genes were included in the 5 Desulfuromonas genomes in this study, the AOP6 and $2873^{\mathrm{T}}$ genomes conserved more abundant homologous genes of omcI than the other genomes. In contrast, the anode-stimulated strains seemed to possess multiple copies of $i m c H ~(2,3$ and 4 copies for the strains WTL, DDH964 and TF, respectively). Despite the presence of commonly conserved $c$-type cytochromes, a large

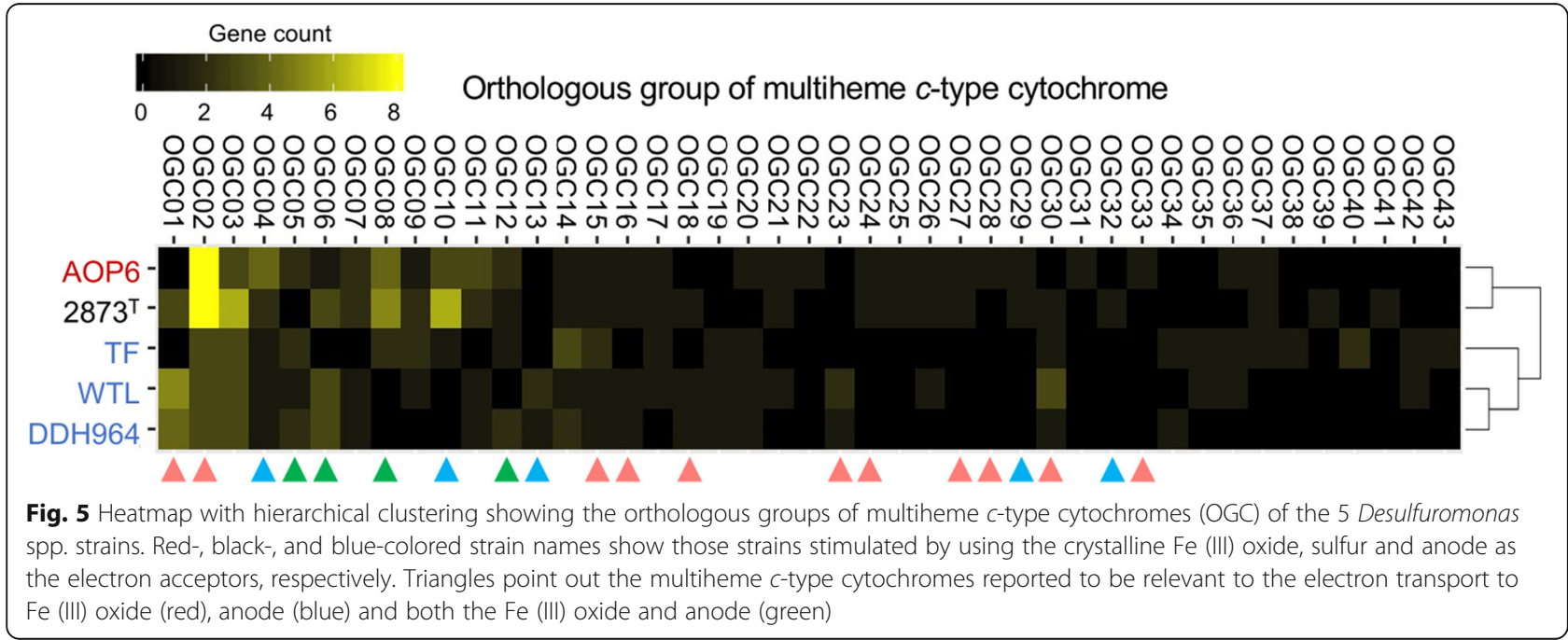


number of OGCs specific to these strains may have formed distinct electron transport ways to different electron acceptors (Fig. 5).

Previous studies revealed that the porin cytochrome conduit (Pcc) complexes acted as conduits for transporting electron across the outer membrane in the Geobacter species, which consisted of the periplasmic multiheme $c$ type cytochromes, porin-like outer membrane protein and outer membrane $c$-type cytochrome [62,63]. In the case of G. sulfurreducens, the putative Pcc complexs ombB-omaB-omcB were needed for electron transport to Fe (III) oxides [59, 64]. OmcB, an outer membrane lipoprotein $c$-type cytochrome of the ombB-omaB-omcB complex, was thought to transfer electrons to the terminal reductases, such as extracellular multiheme $c$-type cytochromes $[62,65]$. Additionally, the homolog of OmcB in Desulfuromonas acetoxidans was able to directly bind to the Ag electrode and promoted electron transport at the biofilm-electrode interface [66]. In this study, the Desulfuromonas spp. strains AOP6, DDH964 and TF possessed the complete gene cluster for the ombB-omaB-omcB complex (data not shown), while the strains $2873^{\mathrm{T}}$ and WTL lacked the $\operatorname{omcB}$ (OGC05) and $o m b B$ (OGC12) genes, respectively (Fig. 5). Another Pcc complex ext $A B C D$ might be required for electrode respiration but not for Fe (III) oxide reduction [19]. The genomes of the strains AOP6 and $2873^{\mathrm{T}}$ possessed the homologous genes for extA (OGC10) encoding the periplasmic cytochrome $c$, while the WTL and DDH964 genomes possessed the extC homologs (OGC13) encoding the outer membrane cytochrome $c$; however, none of the 5 strains possessed the complete ext $A B C D$ complex gene cluster. Some of singleton genes for other periplasmic cytochrome $c$ of certain Pcc complex were also found in the genomes of the 5 strains: $p c c F$ (OGC07) in the strains AOP6, $2873 \mathrm{~T}$, WTL and DDH943, and extK (OGC29) in the strains AOP6 and $2873^{\mathrm{T}}$.

Other genes encoding the outer membrane $c$-type cytochromes, such as omcO (OGC01), omcP (OGC06), omcS (OGC08) and omcZ (OGC32), were found in the 5 genomes (Fig. 5). OmcO and OmcP appeared to be irrelevant to $\mathrm{Fe}$ (III) oxide reduction by G. sulfurreducens [59], but their homologs were relevant to that by $G$. metallireducens [67], indicating that these $c$-type cytochromes may have played different functional roles in these species. In this study, the anode-stimulated strains WTL and DDH964 possessed multiple copies of the omcO and omcP genes, but the ferric iron oxidestimulated AOP6 possessed only one copy of omcP. Meanwhile, OmcS required for both Fe (III) oxide reduction [65] and electrode respiration [68] bound to epili as catalyzing the terminal electron transfer [69]. Recent studies showed that OmcS also formed the cytochrome-based filaments capable of transporting electron for long distances over micrometers [14, 15]. Here, multiple homologs of OmcS were found in the strains AOP6, $2873^{\mathrm{T}}$ and TF, but not WTL and DDH964. Further, OmcZ was reported to participate in electron transport to anode with thick biofilm $(>50 \mu \mathrm{m})$ [70], but not to anode with thin biofilm and Fe (III) oxides by G. sulfurreducens $[59,68]$. Only one gene copy encoding the OmcZ homolog was found in the $2873^{\mathrm{T}}$ genome.

Although the strains WTL and DDH964 did not have the homologs of OmcS and OmcZ, they possessed $p g c A$ (OGC23) and $g s c A$ (OGC30) genes encoding extracellular multiheme $c$-type cytochromes that can serve as terminal reductases [71, 72]. PgcA, a soluble c-type cytochrome, was secreted to environments as electron shuttle [71]. The G. sulfurreducens mutants with deletion of $p g c A$ lost the ability to transfer electrons to the Fe (III) and Mn (IV) oxides, but the same mutants maintained the electrode respiration capability [20], suggesting the enhancement of the metal reductions rather than electrode respiration by PgcA. However, the homolog of PgcA was not found in the genomes of the Fe (III) oxide-stimulated strain AOP6 and sulfide-stimulated strain $2873^{\mathrm{T}}$, but found in the anode-stimulated strains WTL and DDH964. In this context, this gene was also present in the genomes of G. anodireducens SD-1 and G. sulfureducens YM18 that were isolated from an anode biofilm and generated high current densities in bioelectrochemical systems [72, 73].

Menaquinol:ferricytochrome $c$ oxidoreductase $(\mathrm{Cbc})$ complexes, consisting of periplasmic $c$-type cytochromes, $b$-type cytochromes, membrane proteins and other $c$-type cytochromes, were also associated with reduction of the Fe (III) and Mn (IV) oxides in the Geobacter species [59]. In this study, the genes $c b c A$ (OGC17), $\quad c b c M$ (OGC21), $\quad c b c N$ (OGC24), $c b c R$ (OGC25), $c b c S$ (OGC19), and $c b c X$ (OGC20) encoding the $c$-type cytochromes of $\mathrm{Cbc}$ complexes were found in the 5 genomes (Fig. 5). Reportedly, the expressions of the $c b c A, c b c N$ and $c b c X$ genes for the periplasmic $c$-type cytochromes were up-regulated in G. sulfurreducens with Fe (III) oxide versus Fe (III) citrate [59]. It was noteworthy that only the Fe (III) oxide-stimulated strain AOP6 possessed all of these three genes.

A number of other genes encoding $c$-type cytochromes found in the 5 genomes were reported to be significantly up-regulated when Fe (III) oxide was used as electron acceptor, which includes the nrfA (OGC09), $n r f H$ (OGC26) genes in G. sulfurreducens [59], as well as the unnamed genes Gmet_1867 (OGC16), Gmet_0142 (OGC18) and Gmet_0679 (OGC27) in G. metallireducens [67]. However, no further evidence can support an association between the arrangements of these genes and the $\mathrm{Fe}$ (III) oxide reduction activity. In addition, the 
other genes for $c$-type cytochromes (OGC31 and OGC33-43) were also present in some of the 5 genomes (Fig. 5). The homologs of these genes were almost found in the genomes of the Desulfuromonas species, but absent in those of the Geobacter species (data not shown). Their roles in extracellular electron transport warrant the future study. Consequently, our analysis indicated that the multiheme $c$-type cytochrome profiles were obviously different among the phylogenetically close Desulfuromonas spp. strains. The Fe (III)-oxide stimulated strains possessed more abundant and diverse $c$-type cytochromes than the anode-stimulated strains. Particularly, the periplasmic and outer membrane cytochromes represented strain- and/or cluster-specific patterns, which may have linked with electron transports to the iron (III) oxide and anode with different redox potentials.

\section{Cytochrome oxidase and ROS detoxifying enzyme}

Although most of members in the families Geobaceteraceae and Desulfuromonadaceae are strictly anaerobic $[37,74]$, some of them show the ability to detoxify reactive oxygen species (ROS) and resist low concentrations (e.g., 10\%) of oxygen [27, 29, 75, 76]. G. sulfurreducens sigma factor RpoS contributed to survival in stationary phase and upon oxygen exposure [75]. RpoS activated the $c a a_{3}$-type cytochrome $c$ oxidase operon, which encodes a heme-copper terminal oxidase for the G. sulfurreducens growth using oxygen as an electron acceptor [77]. The caa3-type oxidase encoded by $\operatorname{cox} A B C D$ was found in the genomes of G. sulfurreducens [10], G. metallireducens [54], Geomonas bemidjiensis (previously named as Geobacter bemijiensis) [40, 78], and Desulfuromonas sp. TF [27]. On the other hand, the $c b b_{3}$-type cytochrome $c$ oxidase (CcoNOPQ) with high affinity for oxygen was expressed under low oxygen tension conditions [79], and the genes encoding this oxidase were conserved in the genomes of Gm. bemidjirensis and Desulfuromonas sp. TF [27, 78].

Intriguingly, in this study, the gene sets for these two types of oxidases were present in the genomes of the strains WTL, DDH964 and TF, but absent in those of the strains AOP6 and $2873^{\mathrm{T}}$ except for the homologous genes of $c c o P$ that encodes the diheme cytochrome $c$ subunit (subunit III) of $c b b_{3}$-type oxidase (Table 4). Moreover, the anode-stimulated strains possessed multiple homologs of CcoP: 6 in the strain WTL, 4 in DDH964, and 4 in TF. Pseudomonas aeruginosa, a ubiquitous opportunistic human pathogen, expressed multiple $c b b_{3}$-type cytochrome $c$ oxidase isoforms by combinations of multiple isosubunits, and the strains carrying these isoforms can resist to respiratory inhibitors such as nitrite and cyanide at low concentrations of oxygen [80]. Despite only one $c c o N$ gene encoding the catalytic subunit possessed by the anode-stimulated strains, there was still possibility that they produced 4 to $6 c b b_{3}$ isoforms by combinations with different CcoP isosubunits. Such multiple $c c b_{3}$ isoforms may have brought a diverse array for oxidative stress responses for the anode-stimulated strains. Additionally, the $c y d A B$ genes encoding cytochrome $b d$ quinol oxidase complex was found in the 5 genomes (Table 4), which is related to the provision of the trace oxygen tolerance [27]. Genes involved in the ROS detoxification, e.g., the genes for rubrerythrin $(r b r)$, rubredoxin $(r u b)$, desulfoferredoxin $(d f x)$, and cytochrome $c$ peroxidase (macA), abundantly existed in the 5 genomes (Table 4). It was reported that these genes were significantly expressed in G. uraniireducens exposed to 5\% oxygen revealed by microarray analysis [81]. Overall, comparative genome analysis showed that the $c a a_{3^{-}}$and $c b b_{3}$-type cytochrome $c$ oxidases appeared to be specific to the anodestimulated strains WTL, DDH964 and TF. They also possessed other diverse genes involved in oxygen resistance and ROS detoxification. These genetic features would confer high oxygen resistance in the strictly anaerobic bacteria, contributing to the niche differentiation of the phylogenetically close Desulfuromonas spp. strains. Reportedly, the anode-stimulated strain WTL originally inhabited in the anoxic (but not strictly anaerobic) environments at the Soudan Iron Mine borehole and it was able to survive under the unplanned oxygen exposures, due to power outage in laboratory [29], which partially supports the genomic inference.

\section{Transposable element}

Transposable elements (TEs) are usually found in the genomes of bacterial symbionts, which initially undergo massive expansion and then loss accompanied by gene inactivation and decay, genome rearrangement and genome reduction [82-85]. The large genome rearrangement and deletions associated with insertion sequence (IS) expansion enabled the symbiotic bacterium to combat host defenses by changing surface antigens and regulatory circuitry [86, 87]. Similar patterns of this genome evolution were detected in cases of some nicherestricted prokaryotes such as Sulfolobus solfataricus and certain Cyanobacteria species [88-90].

The anode-stimulated strains WTL and DDH964 possessed large numbers of TEs, particularly transposaseencoding genes that accounted for 2.2 and $3.1 \%$ of the total coding sequences in the genomes, respectively, whereas the Fe (III) oxide-stimulated strain AOP6 only contains 10 of these genes in the genome $(0.3 \%$ of the total) (Fig. 3). In addition, most of the transposaseencoding genes were located nearby the pseudogenes in the WTL and DDH964 genomes (Fig. 3), suggesting that the repeated insertion-deletion of transposons induced 
Table 4 Genes encoding cytochrome c oxidases, cytochrome bd oxidase, and ROS detoxifying enzymes in the five Desulfuromonas genomes

\begin{tabular}{|c|c|c|c|c|c|c|}
\hline \multirow[b]{2}{*}{ Gene } & \multirow[b]{2}{*}{ Product } & \multicolumn{5}{|c|}{ Locus tag in the genomes of Desulfuromonas spp. strains } \\
\hline & & AOP6 & $2873^{\top}$ & WTL & DDH964 & TF \\
\hline SCO & $\begin{array}{l}\mathrm{Caa}_{3} \text { cytochrome } \mathrm{c} \text { oxidase } \\
\text { synthesis factor }\end{array}$ & - & - & DSOUD_0978 & DBW_3007 & DTF_RS0106035 \\
\hline $\operatorname{cox} A$ & $\begin{array}{l}\mathrm{Caa}_{3} \text { cytochrome } \mathrm{c} \text { oxidase, } \\
\text { subunit I }\end{array}$ & - & - & DSOUD_0979 & DBW_3008 & DTF_RS0106040 \\
\hline $\operatorname{cox} B$ & $\begin{array}{l}\mathrm{Caa}_{3} \text { cytochrome } \mathrm{c} \text { oxidase, } \\
\text { subunit II }\end{array}$ & - & - & DSOUD_0982 & DBW_3011 & DTF_RS0106055 \\
\hline $\operatorname{coxC}$ & $\begin{array}{l}\mathrm{Caa}_{3} \text { cytochrome } \mathrm{c} \text { oxidase, } \\
\text { subunit III }\end{array}$ & - & - & DSOUD_0980 & DBW_3009 & DTF_RS0106045 \\
\hline $\operatorname{cox} D$ & $\begin{array}{l}\mathrm{Caa}_{3} \text { cytochrome } \mathrm{c} \text { oxidase, } \\
\text { subunit IV }\end{array}$ & - & - & DSOUD_0981 & DBW_3010 & DTF_RS0106050 \\
\hline$c t a B$ & $\begin{array}{l}\text { Proteheme IX } \\
\text { farnesyltransferase }\end{array}$ & - & - & DSOUD_0983 & DBW_3012 & DTF_RS25235 \\
\hline- & Rubrerythrin & AOP6_2408 & BQ4888_RS16015 & DSOUD_0984 & DBW_3013 & DTF_RS0102535 \\
\hline$d f x$ & $\begin{array}{l}\text { Desulfoferredoxin (superoxide } \\
\text { reductase) }\end{array}$ & AOP6_2409 & BQ4888_RS16020 & DSOUD_0985 & DBW_3014 & - \\
\hline $\mathrm{CCON}$ & $\begin{array}{l}\mathrm{Cbb}_{3} \text { cytochrome } c \text { oxidase, } \\
\text { subunit I }\end{array}$ & - & - & DSOUD_2312 & DBW_2371 & DTF_RS0116565 \\
\hline $\mathrm{CCOO}$ & $\begin{array}{l}\mathrm{cbb}_{3} \text { cytochrome } c \text { oxidase, } \\
\text { subunit II }\end{array}$ & - & - & DSOUD_2313 & DBW_2372 & DTF_RS0116570 \\
\hline $\mathrm{CCOP}$ & $\begin{array}{l}c b b_{3} \text { cytochrome } c \text { oxidase, } \\
\text { subunit III }\end{array}$ & AOP6_0637 & BQ4888_RS14340 & DSOUD_2315 & DBW_2374 & DTF_RS26690 \\
\hline $\mathrm{CCOQ}$ & $\begin{array}{l}\mathrm{cbb}_{3} \text { cytochrome } \mathrm{c} \text { oxidase } \\
\text { assembly chaperone }\end{array}$ & - & - & DSOUD_2314 & DBW_2373 & DTF_RS26685 \\
\hline $\operatorname{ccos}$ & $\begin{array}{l}c b b_{3} \text { cytochrome } c \text { oxidase } \\
\text { assembly protein } C \cos \end{array}$ & - & - & DSOUD_2319 & DBW_2378 & DTF_RS0116600 \\
\hline- & $\begin{array}{l}c b b_{3} \text { cytochrome } c \text { oxidase, } \\
\text { subunit III }\end{array}$ & $\begin{array}{l}\text { AOP6_0462, AOP6_1193, } \\
\text { AOP6_1768, AOP6_2692 }\end{array}$ & $\begin{array}{l}\text { BQ4888_RS04845, } \\
\text { BQ4888_RS07140 }\end{array}$ & DSOUD_0601 & DBW_0838 & DTF_RS0119470 \\
\hline- & $\begin{array}{l}c b b_{3} \text { cytochrome c oxidase, } \\
\text { subunit III }\end{array}$ & - & - & DSOUD_0719 & - & - \\
\hline - & $\begin{array}{l}c b b_{3} \text { cytochrome } c \text { oxidase, } \\
\text { subunit III }\end{array}$ & - & BQ4888_RS10570 & $\begin{array}{l}\text { DSOUD_0327, DSOUD_ } \\
1618\end{array}$ & DBW_3541 & DTF_RS25165 \\
\hline- & $\begin{array}{l}c b b_{3} \text { cytochrome } c \text { oxidase, } \\
\text { subunit III }\end{array}$ & AOP6_1494 & - & - & - & - \\
\hline- & $\begin{array}{l}c b b_{3} \text { cytochrome } c \text { oxidase, } \\
\text { subunit III }\end{array}$ & AOP6_2835 & - & DSOUD_0081 & DBW_3572 & DTF_RS0100735 \\
\hline cydA & $\begin{array}{l}\text { cytochrome bd ubiquinol } \\
\text { oxidase subunit I }\end{array}$ & AOP6_2873 & BQ4888_RS11725 & DSOUD_0336 & DBW_0564 & DTF_RS22095 \\
\hline$c y d B$ & $\begin{array}{l}\text { cytochrome bd ubiquinol } \\
\text { oxidase subunit II }\end{array}$ & AOP6_2874 & BQ4888_RS11720 & DSOUD_0335 & DBW_0565 & DTF_RS0105770 \\
\hline rub & Rubredoxin & AOP6_0414, AOP6_0415 & BQ4888_RS07685 & DSOUD_3135 & DBW_3237 & DTF_RS25905 \\
\hline- & $\begin{array}{l}\text { Desulfoferredoxin (superoxide } \\
\text { reductase) }\end{array}$ & AOP6_2966 & - & DSOUD_0362 & DBW_3006 & - \\
\hline rbr & Rubrerythrin & AOP6_0339 & BQ4888_RS13615 & DSOUD_0365 & DBW_3641 & DTF_RS0115795 \\
\hline sodA & Superoxide dismutase & - & BQ4888_RS04500 & - & - & - \\
\hline macA & Cytochrome $c$ peroxidase & AOP6_0104, AOP6_0558 & $\begin{array}{l}\text { BQ4888_RS09810, } \\
\text { BQ4888_RS15550 }\end{array}$ & $\begin{array}{l}\text { DSOUD_0544, DSOUD_ } \\
\text { 1166, DSSOUD_2534 }\end{array}$ & DBW_1968 & DTF_RS0118780 \\
\hline
\end{tabular}


the loss of some of functional genes, such as those encoding the transcriptional regulator, RNA methyltransferase, ATPase, polysulfide reductase and methylaccepting chemotaxis protein (data not shown). Meanwhile, 31 and 6 transposase-encoding genes were also found in the $2873^{\mathrm{T}}$ and TF genomes; however, due to the highly fragmented assemblies of the strains $2873^{\mathrm{T}}$ and TF (consisting of 41 and 167 contigs, respectively), the absolute counts of TEs would be underestimated [84]. Thus, these results only suggest an expansion of TEs in the genomes of the strains WTL and DDH964.

In order to better understand the pattern of TEs, the predicted transposase genes were classified by IS family. This analysis showed that the transposase genes in the WTL genome were mainly affiliated to families IS1595, IS3 and IS4, while those in the DDH964 genome were predominately from families IS256, IS4, IS200/IS605, IS21, IS110, IS3, and others (Fig. 6). The distinct profiles of IS family between the two genomes suggested that these anode-stimulated strains may have independently undergone the TE expansions. Our analysis identified the abundant and diverse transposons spread across the genomes of the anode-stimulated WTL and DDH964 (Figs. 3 and 6). Other important features were (i) the absence of the gene cluster for flagellar biosynthesis (see section 2) and (ii) the presence of diverse genes involved in oxygen resistance and ROS detoxification (see section 5) in these two genomes. We speculated that, when the flagellar gene cluster is lost from the Desulfuromonas genome, the bacterial mobility would be decreased and the cells would be restricted in specific habitats with relatively constant conditions, such as existing simple types of electron acceptors. This situation may trigger the transposon-mediated genome rearrangement that results in the selection of the essential genes for this specific habitat and the elimination of other unnecessary genes from the genome. However, the genome sizes of the strains WTL and DDH996 are larger than those of the strains AOP6 and $2873^{\mathrm{T}}$, indicating the gene acquisition and enrichment may have also occurred during the genome rearrangement. It is likely that the decrease in mobility also affects the ability of escaping from the abrupt change in environment conditions, for example the exposure to oxygen, so that the genes involved in stress resistance would be gained and enriched in the genome. Interestingly, it was reported that the genes involved in the formation of pili and flagella, as well as chemotaxis sensory regulators, in G. uraniireducens were significantly down-regulated under oxidative stress conditions, while those for oxygen resistant enzymes were up-regulated under the same conditions [81], implying the opposite relationship between the expression of these genes. This evolutionary scenario partially explained that the strains AOP6 and $2873^{\mathrm{T}}$ possessed more numerous numbers and types of the genes involved in chemotaxis and $c$-type cytochrome, while the strains WTL and DDH964 had more diverse genes for oxygen resistance.

\section{Conclusions}

In this study, we carried out comparative genome analysis to identify the different genomic signatures between ferric iron oxide- and anode-stimulated Desulfuromonas spp. strains. The results indicated that the compared 5 genomes possessed distinct gene sets responsible for flagellar biosynthesis, chemotaxis, electron transfer, oxygen resistance and genome rearrangement. Particularly, the crystalline Fe (III) oxide-stimulated strain AOP6 would exhibit the flagellum-based mobility with more diverse chemotaxis sensory systems and more abundant $c$-type cytochromes for reduction of electron acceptors with low redox potentials. On the other hand, the anode-

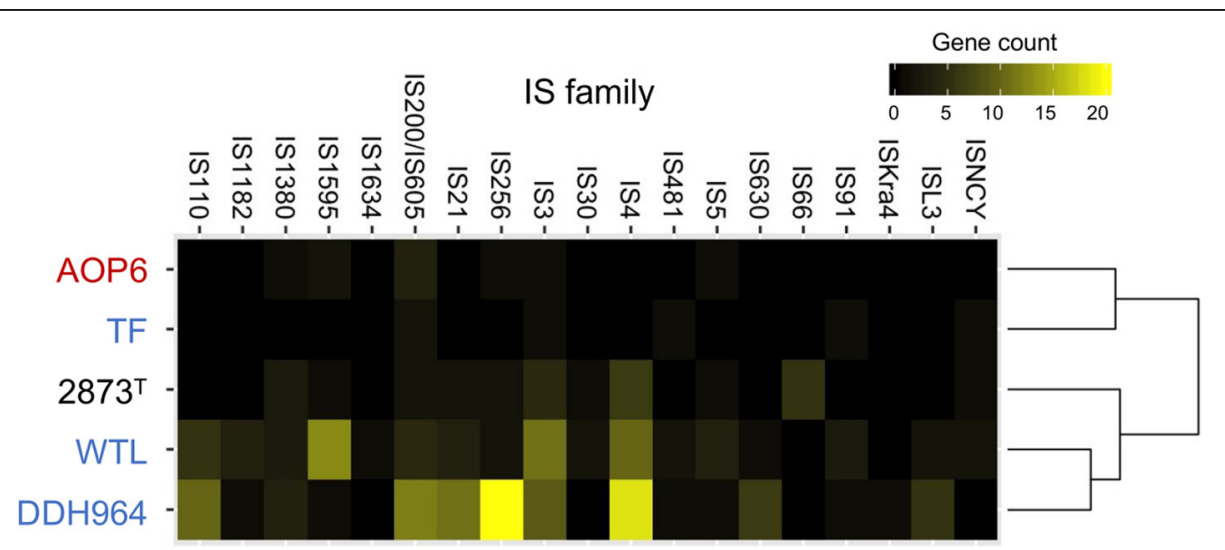

Fig. 6 Heatmap with hierarchical clustering showing the insertion sequence (IS) families of the transposases detected in the 5 Desulfuromonas spp. strains. Red-, black-, and blue-colored strain names show those strains stimulated by using the crystalline Fe (III) oxide, sulfur and anode as the electron acceptors, respectively 
stimulated strains WTL and DDH964 lacking the flagellum-based mobility likely weakened the ability to use the low redox potential electron acceptors but enabled to survive under oxygen exposure. Moreover, the transposon expansions would mediate the genome rearrangements in the strains WTL and DDH964 genomes. These findings cast light on genome evolution of the phylogenetically close Desulfuromonas spp. strains that are involved in metal reduction in subsurface environments.

\section{Methods}

\section{Genome-wide phylogeny of the order Desulfuromonadales}

In order to perform a genome-wide phylogenetic analysis, all the available genomes (50 genomes in total) affiliated with the order Desulfuromonadales were obtained from GenBank/DDBJ/EMBL on March 11, 2020. Single copy marker genes were inferred using OrthoFinder v2.3.3 [91], and the amino acid sequences deduced from these genes were used to perform a multilocus sequence analysis as previously reported $[84,85]$, with minor modifications. In brief, multiple sequences alignments were inferred for each gene using MAFFT v7.455 [92] and concatenated for phylogenetic analysis. An approximately-maximumlikelihood phylogenetic tree was generated using FastTree v2.1.10 with the Gamma20 model [93]. FigTree v1.4.4 (https://github.com/rambaut/figtree) was used for the visualization of the tree.

\section{Comparative genomics}

In an attempt to investigate the genomic features for the closely related Desulfuromonas spp. strains with different enrichment approaches, the complete genome sequences of the strains AOP6, WTL, and DDH964, as well as the draft sequences of strains $2873^{\mathrm{T}}$ and TF, were selected for comparative genomic analysis (Table 1). In order to refine the previous annotations of these 5 genomes, the amino acid sequences deduced from all of the genes were analyzed using the KofamKOALA [94] and MOTIF searches against the sequence libraries Pfam (https:// www.genome.jp/tools/motif), NCBI-CDD and PROSITE. Pairwise ANI and AAI among the 5 genomes were determined using the BLAST-based JspeciesWS [95] and online AAI calculator (http://enve-omics.ce.gatech.edu/ aai/), respectively. The OGs across the 5 genomes were phylogenetically inferred using the OrthoFinder with the option of 'diamond', an accelerated sequence aligner that has a comparable sensitivity to the BLASTX. The presence or absence of genes was evaluated by determining whether or not the genome possessed the correspondent OG. A heatmap with hierarchical clustering based on the Bray-Curtis similarities on the R platform (https:// www.r-project.org/) with the gplots package v.3.0.3 (https://cran.r-project.org/web/packages/gplots/index. html) was used to show the OG distribution across the 5 genomes. The predicted OGs were manually sorted based on the physical locations and directions in the 3 complete genomes to estimate the genomic difference and rearrangement. Circos v0.69 [96] was used to visualize the syntenic comparative analysis data of the AOP6 genome versus the WTL and DDH964 genomes.

Chemotaxis genes were identified using Microbial Signal Transduction Database (MiST) 3.0 [48]. The identified genes were sorted based on the orthologous groups to evaluate the presence or absence of the chemotaxis genes in each genome. The class membership of the MCP was assessed by the number of heptad repeats $(\mathrm{H})$ in the cytoplasmic domain [50]. The organization of chemotaxis operons in the Desulfuromoas spp. strains was predicted using FGENESB (http://www.softberry. com/berry.phtml) with the previously described algorithm [22]. Multiheme $c$-type cytochromes $(\geq 3 \mathrm{Cxx}[\mathrm{x}]$ $\mathrm{H}$ motifs) were identified with the Python script reported previously [29]. The predicted multiheme $c$-type cytochromes were sorted based on the orthologous groups to generate a heatmap with hierarchical clustering mentioned above. The family membership of predicted transposases was assessed using ISfinder [97] and indicated as a heatmap with hierarchical clustering mentioned above. Pseudogenes were identified with the NCBI prokaryotic genome annotation pipeline employing a two-pass approach to detect frameshifted genes and pseudogenes with the premature stop codon [98].

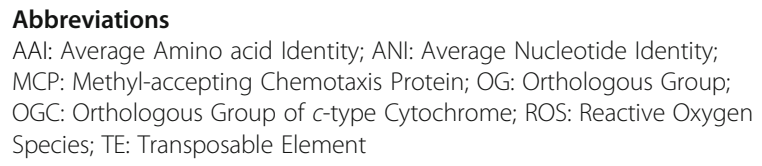

\section{Supplementary Information}

The online version contains supplementary material available at https://doi. org/10.1186/s12864-021-07809-6.

\section{Additional file 1.}

\section{Acknowledgements}

Not applicable.

\section{Authors' contributions}

YG, TA and TH contributed to the conception, investigation and design of the study. YG performed the bioinformatic analyses and wrote the draft manuscript. TA and TH contributed to acquire the funding, discuss the results, and revise the manuscript. The author(s) read and approved the final manuscript.

\section{Funding}

This work was supported in part by Japan Society for the Promotion of Science (JSPS) KAKENHI grants (numbers 16H05886, $18 \mathrm{K18184}$, and 19H04244) and by research grants from the Institute for Fermentation, Osaka (IFO), to Tomo Aoyagi and Tomoyuki Hori. 


\section{Availability of data and materials}

All data analyzed in this study are available through NCBI GeneBank and RefSeq databases, are accessible through the accession numbers listed in Table 1 for the major data and in Table S1 for all the data, respectively.

\section{Declarations}

Ethics approval, accordance and consent to participate Not applicable.

\section{Consent for publication}

Not applicable.

\section{Competing interests}

The authors declare that they have no competing interests.

Received: 11 February 2021 Accepted: 15 June 2021

Published online: 25 June 2021

\section{References}

1. Aburto-Medina A, Ball AS. Microorganisms involved in anaerobic benzene degradation. Ann Microbiol. 2015;65(3):1201-13. https://doi.org/10.1007/ s13213-014-0926-8.

2. Coates JD, Lonergan DJ, Philips EJP, Jenter H, Lovley DR. Desulfuromonas palmitatis sp. nov., a marine dissimilatory Fe (III) reducer that can oxidize long-chain fatty acids. Arch Microbiol. 1995;164(6):406-13. https://doi.org/1 $0.1007 / B F 02529738$

3. Hori T, Müller A, Igarashi Y, Conrad R, Friedrich MW. Identification of ironreducing microorganisms in anoxic rice paddy soil by ${ }^{13} \mathrm{C}$-acetate probing ISME J. 2010;4(2):267-78. https://doi.org/10.1038/ismej.2009.100.

4. Wagner DD, Hug LA, Hatt JK, Spitzmiller MR, Padilla-Crespo E, Ritalahti KM, et al. Genomic determinants of organohalide-respiration in Geobacter lovleyi, an unusual member of the Geobacteraceae. BMC Genomics. 2012;13(1):200. https://doi.org/10.1186/1471-2164-13-200.

5. Ohtsuka T, Yamaguchi N, Makino T, Sakurai K, Kimura K, Kudo K, et al. Arsenic dissolution from Japanese paddy soil by a dissimilatory arsenatereducing bacterium Geobacter sp. OR-1. Environ Sci Technol. 2013;47(12): 6263-71. https://doi.org/10.1021/es400231X.

6. Couture RM, Charlet L, Markelova E, Madé B, Parsons CT. On-off mobilization of contaminants in soils during redox oscillations. Environ Sci Technol. 2015; 49(5):3015-23. https://doi.org/10.1021/es5061879.

7. Schlesinger WH, Cole JJ, Finzi AC, Holland EA. Introduction to coupled biogeochemical cycles. Front Ecol Environ. 2011;9(1):5-8. https://doi.org/10.1 890/090235

8. Buongiorno J, Herbert LC, Wehrmann LM, Michaud AB, Laufer K, Røy H, et al. Complex microbial communities drive iron and sulfur cycling in Arctic Fjord sediments. Appl Environ Microbiol. 2019;85(14):e00949-19. https://doi. org/10.1128/AEM.00949-19.

9. Yee MO, Deutzmann J, Spormann A, Rotaru AE. Cultivating electroactive microbes-from field to bench. Nanotechnology. 2020;31(17):174003. https:// doi.org/10.1088/1361-6528/ab6ab5.

10. Methé BA, Nelson KE, Eisen JA, Paulsen IT, Nelson W, Heidelberg JF, et al. Genome of Geobacter sulfurreducens: metal reduction in subsurface environments. Science. 2003;302(5652):1967-9. https://doi.org/10.1126/ science. 1088727.

11. Reguera G, McCarthy KD, Mehta T, Nicoll JS, Tuominen MT, Lovley DR. Extracellular electron transfer via microbial nanowires. Nature. 2005. 435(7045):1098-101. https://doi.org/10.1038/nature03661.

12. Butler JE, Young ND, Lovley DR. Evolution of electron transfer out of the cell: comparative genomics of six Geobacter genomes. BMC Genomics. 2010; 11(1):40. https://doi.org/10.1186/1471-2164-11-40.

13. Butler JE, Young ND, Aklujkar M, Lovley DR. Comparative genomic analysis of Geobacter sulfurreducens KN400, a strain with enhanced capacity for extracellular electron transfer and electricity production. BMC Genomics. 2012;13(1):471. https://doi.org/10.1186/1471-2164-13-471.

14. Wang F, Gu Y, O'Brien JP, Yi SM, Yalcin SE, Srikanth V, et al. Structure of microbial nanowires reveals stacked hemes that transport electrons over micrometers. Cell. 2019;177:361-369.e10. https://doi.org/10.1016/j.cell.2019, 03.029.

15. Filman DJ, Marino SF, Ward JE, Yang L, Mester Z, Bullitt E, et al. Cryo-EM reveals the structural basis of long-range electron transport in a cytochrome-based bacterial nanowire. Commun Biol. 2019;2(1):219. https:// doi.org/10.1038/s42003-019-0448-9.

16. Lovley DR, Walker DJF. Geobacter protein nanowires. Front Microbiol. 2019; 10:2078 https://doi.org/10.3389/fmicb.2019.02078.

17. Shi L, Dong H, Reguera G, Beyenal H, Lu A, Liu J, et al. Extracellular electron transfer mechanisms between microorganisms and minerals. Nat Rev Microbiol. 2016;14(10):651-62. https://doi.org/10.1038/nrmicro.2016.93.

18. Otero FJ, Chan CH, Bond DR. Identification of different putative outer membrane electron conduits necessary for Fe (III) citrate, Fe (III) oxide, Mn (IV) oxide, or electrode reduction by Geobacter sulfurreducens. J Bacteriol. 2018;200(19):e00347-18. https://doi.org/10.1128/JB.00347-18.

19. Chan CH, Levar CE, Jiménez-Otero F, Bond DR. Genome scale mutational analysis of Geobacter sulfurreducens reveals distinct molecular mechanisms for respiration and sensing of poised electrodes versus Fe (III) oxides. J Bacteriol. 2017;199(19):e00340-17. https://doi.org/10.1128/JB.00340-17.

20. Zacharoff $L A$, Morrone DJ, Bond DR. Geobacter sulfurreducens extracellular multiheme cytochrome PgcA facilitates respiration to Fe (III) oxides but not electrodes. Front Microbiol. 2017;8:2481. https://doi.org/10.3389/fmicb.2017. 02481.

21. Childers SE, Ciufo S, Lovley DR. Geobacter metallireducens accesses insoluble Fe (III) oxide by chemotaxis. Nature. 2002;416(6882):767-9. https://doi.org/1 $0.1038 / 416767 a$

22. Tran HT, Krushkal J, Antommattei FM, Lovley DR, Weis RM. Comparative genomics of Geobacter chemotaxis genes reveals diverse signaling function. BMC Genomics. 2008;9(1):471. https://doi.org/10.1186/1471-2164-9-471.

23. Roden EE, Lovley DR. Dissimilatory Fe (III) reduction by the marine microorganism Desulfuromonas acetoxidans. Appl Environ Microbiol. 1993; 59:734-42. https://doi.org/10.1128/aem.59.3.734-742.1993.

24. Schink B. Fermentation of acetylene by an obligate anaerobe, Pelobacter acetylenicus sp. nov. Arch Microbiol. 1985;142(3):295-301. https://doi.org/1 0.1007/BF00693407.

25. Dehning I, Schink B. Malonomonas rubra gen. Nov. sp. nov., a microaerotolerant anaerobic bacterium growing by decarboxylation of malonate. Arch Microbiol. 1989;151(5):427-33. https://doi.org/10.1007/ BF00416602.

26. Liesack W, Finster K. Phylogenetic analysis of five strains of gram-negative, obligately anaerobic, sulfur-reducing bacteria and description of Desulfuromusa gen. Nov., including Desulfuromusa kysingii sp. nov., Desulfuromusa bakii sp. nov., and Desulfuromusa succinoxidans sp. Int I Syst Bacteriol. 1994;44(4):753-8. https://doi.org/10.1099/00207713-44-4-753.

27. Kim SJ, Park SJ, Cha IT, Min D, Kim JS, Chung WH, et al. Metabolic versatility of toluene-degrading, iron-reducing bacteria in tidal flat sediment, characterized by stable isotope probing-based metagenomic analysis. Environ Microbiol. 2014;16(1):189-204. https://doi.org/10.1111/1462-2920.12277.

28. Greene AC, Patel BKC, Yacob S. Geoalkalibacter subterraneus sp. nov., an anaerobic Fe (III)- and Mn (IV)-reducing bacterium from a petroleum reservoir, and emended descriptions of the family Desulfuromonadaceae and the genus Geoalkalibacter. Int J Syst Evol Microbiol. 2009;59(4):781-5. https://doi.org/10.1099/ijs.0.001537-0.

29. Badalamenti JP, Summers ZM, Chan CH, Gralnick JA, Bond DR. Isolation and genomic characterization of "Desulfuromonas soudanensis WTL", a metaland electrode-respiring bacterium from anoxic deep subsurface brine. Front Microbiol. 2016;7:913. https://doi.org/10.3389/fmicb.2016.00913.

30. An TT, Picardal FW. Desulfuromonas carbonis sp. nov., an Fe (III)-, $S^{0}$ - and Mn (IV)-reducing bacterium isolated from an active coalbed methane gas well. Int J Syst Evol Microbiol. 2015;65(Pt_5):1686-93. https://doi.org/10.1099/ijs.0. 000159.

31. Zavarzina DG, Kolganova T V., Boulygina ES, Kostrikina NA, Tourova TP, Zavarzin GA. Geoalkalibacter ferrihydriticus gen. nov. sp. nov., the first alkaliphilic representative of the family Geobacteraceae, isolated from a soda lake. Microbiology. 2006;75:673-82. https://doi.org/10.1134/S0026261 706060099 .

32. Finster K, Bak F, Pfennig N. Desulfuromonas acetexigens sp. nov., a dissimilatory sulfur-reducing eubacterium from anoxic freshwater sediments. Arch Microbiol. 1994;161(4):328-32. https://doi.org/10.1007/BF00303588.

33. Grattieri M, Minteer SD. Microbial fuel cells in saline and hypersaline environments: advancements, challenges and future perspectives. Bioelectrochemistry. 2018;120:127-37 https://doi.org/10.1016/.bioelechem.2 017.12.004

34. Hori T, Aoyagi T, Itoh H, Narihiro T, Oikawa A, Suzuki K, et al. Isolation of microorganisms involved in reduction of crystalline iron (III) oxides in 
natural environments. Front Microbiol. 2015;6:386. https://doi.org/10.3389/ fmicb.2015.00386.

35. Guo Y, Aoyagi T, Inaba T, Sato Y, Habe H, Hori T. Complete genome sequence of Desulfuromonas sp. strain AOP6, an iron (III) eeducer isolated from subseafloor sediment. Microbiol Resour Announc. 2020;9(12):e0132519. https://doi.org/10.1128/MRA.01325-19.

36. Orsetti S, Laskov C, Haderlein SB. Electron transfer between iron minerals and quinones: estimating the reduction potential of the Fe (II)-goethite surface from AQDS speciation. Environ Sci Technol. 2013;47(24):14161-8. https://doi.org/10.1021/es403658g.

37. Dutta PK, Keller J, Yuan Z, Rozendal RA, Rabaey K. Role of sulfur during acetate oxidation in biological anodes. Environ Sci Technol. 2009;43(10): 3839-45. https://doi.org/10.1021/es803682k.

38. Katuri KP, Albertsen M, Saikaly PE. Draft genome sequence of Desulfuromonas acetexigens strain 2873, a novel anode-respiring bacterium. Genome Announc. 2017;5(9):e01522-16. https://doi.org/10.1128/genomeA. 01522-16.

39. Greene AC. The family Desulfuromonadaceae. In: The Prokaryotes: Deltaproteobacteria and Epsilonproteobacteria. 2014. p. 143-55. https://doi. org/10.1007/978-3-642-39044-9_380.

40. Xu Z, Masuda Y, Itoh H, Ushijima N, Shiratori Y, Senoo K. Geomonas oryzae gen. nov., sp. nov., Geomonas edaphica sp. nov., Geomonas ferrireducens sp. nov., Geomonas terrae sp. nov., four ferric-reducing bacteria isolated from paddy soil, and reclassification of three species of the genus Geobacter as members of Geomonas gen. nov. Front Microbiol. 2019;10:2201. https://doi. org/10.3389/fmicb.2019.02201.

41. Xu Z, Masuda Y, Hayakawa C, Ushijima N, Kawano K, Shiratori Y, et al. Description of three novel members in the family Geobacteraceae, Oryzomonas japonicum gen. nov., sp. nov., Oryzomonas sagensis sp. nov., and Oryzomonas ruber sp. nov. Microorganisms. 2020;8:634. https://doi.org/1 0.3390/microorganisms8050634

42. Konstantinidis KT, Tiedje JM. Genomic insights that advance the species definition for prokaryotes. Proc Natl Acad Sci U S A. 2005;102(7):2567-72. https://doi.org/10.1073/pnas.0409727102.

43. Emms DM, Kelly S. OrthoFinder: solving fundamental biases in whole genome comparisons dramatically improves orthogroup inference accuracy. Genome Biol. 2015;16(1):157. https://doi.org/10.1186/s13059-015-0721-2.

44. Ueki T, Leang C, Inoue K, Lovley DR. Identification of multicomponent histidine-aspartate phosphorelay system controlling flagellar and motility gene expression in Geobacter species. J Biol Chem. 2012;287(14):10958-66. https://doi.org/10.1074/jbc.M112.345041.

45. Vargas M, Kashefi K, Blunt-Harris EL, Lovley DR. Microbiological evidence for Fe (III) reduction on early earth. Nature. 1998;395(6697):65-7. https://doi. org/10.1038/25720.

46. Sousa C, De Lorenzo V, Cebolla A. Modulation of gene expression through chromosomal positioning in Escherichia coli. Microbiology. 1997;143(6):20718. https://doi.org/10.1099/00221287-143-6-2071.

47. Couturier E, Rocha EPC. Replication-associated gene dosage effects shape the genomes of fast-growing bacteria but only for transcription and translation genes. Mol Microbiol. 2006;59(5):1506-18. https://doi.org/1 0.1111/j.1365-2958.2006.05046.x.

48. Gumerov VM, Ortega DR, Adebali O, Ulrich LE, Zhulin IB. MiST 3.0: An updated microbial signal transduction database with an emphasis on chemosensory systems. Nucleic Acids Res. 2020;48:D459-64. https://doi. org/10.1093/nar/gkz988.

49. Wuichet K, Alexander RP, Zhulin IB. Comparative genomic and protein sequence analyses of a complex system controlling bacterial chemotaxis. In: Methods in Enzymology; 2007. p. 3. https://doi.org/10.1016/S00766879(06)22001-9

50. Alexander RP, Zhulin IB. Evolutionary genomics reveals conserved structural determinants of signaling and adaptation in microbial chemoreceptors. Proc Natl Acad Sci U S A. 2007;104(8):2885-90. https://doi.org/10.1073/pnas. 0609359104.

51. Szurmant H, Ordal GW. Diversity in chemotaxis mechanisms among the bacteria and archaea. Microbiol Mol Biol Rev. 2004;68(2):301-19. https://doi. org/10.1128/MMBR.68.2.301-319.2004.

52. Muff TJ, Ordal GW. The diverse CheC-type phosphatases: chemotaxis and beyond. Mol Microbiol. 2008;70(5):1054-61. https://doi.org/10.1111/j.1365-2 958.2008.06482.x.

53. Park SY, Chao X, Gonzalez-Bonet G, Beel BD, Bilwes AM, Crane BR. Structure and function of an unusual family of protein phosphatases: the bacterial chemotaxis proteins CheC and CheX. Mol Cell. 2004;16(4):563-74. https:// doi.org/10.1016/j.molcel.2004.10.018.

54. Aklujkar M, Krushkal J, Dibartolo G, Lapidus A, Land ML, Lovley DR. The genome sequence of Geobacter metallireducens: features of metabolism, physiology and regulation common and dissimilar to Geobacter sulfurreducens. BMC Microbiol. 2009;9(1):109. https://doi.org/10.1186/1471-21 80-9-109.

55. Levar CE, Hoffman CL, Dunshee A, Toner BM, Bond DR. Redox potential as a master variable controlling pathways of metal reduction by Geobacter sulfurreducens. ISME J. 2017;11(3):741-52. https://doi.org/10.1038/ismej.2016.146.

56. Levar CE, Chan CH, Mehta-Kolte MG, Bond DR. An inner membrane cytochrome required only for reduction of high redox potential extracellular electron acceptors. MBio. 2014;5:mBio.02034-14. https://doi.org/10.1128/ mBio.02034-14.

57. Zacharoff L, Chan CH, Bond DR. Reduction of low potential electron acceptors requires the $\mathrm{CbcL}$ inner membrane cytochrome of Geobacter sulfurreducens. Bioelectrochemistry. 2016;107:7-13 https://doi.org/10.1016/j. bioelechem.2015.08.003.

58. Lloyd JR, Leang C, Hodges Myerson AL, Coppi MV, Cuifo S, Methe B, et al. Biochemical and genetic characterization of PpcA, a periplasmic c-type cytochrome in Geobacter sulfurreducens. Biochem J. 2003;369(1):153-61. https://doi.org/10.1042/bj20020597.

59. Aklujkar M, Coppi M V., Leang C, Kim BC, Chavan MA, Perpetua LA, et al. Proteins involved in electron transfer to Fe (III) and $\mathrm{Mn}$ (IV) oxides by Geobacter sulfurreducens and Geobacter uraniireducens. Microbiol (United Kingdom). 2013;159:515-35. https://doi.org/10.1099/mic.0.064089-0.

60. Kato S, Hashimoto K, Watanabe K. Iron-oxide minerals affect extracellular electron-transfer paths of Geobacter spp. Microbes Environ. 2013;28(1):141-8. https://doi.org/10.1264/jsme2.ME12161.

61. Peng L, Zhang XT, Yin J, Xu SY, Zhang Y, Xie DT, et al. Geobacter sulfurreducens adapts to low electrode potential for extracellular electron transfer. Electrochim Acta. 2016;191:743-9 https://doi.org/10.1016/j.electa cta.2016.01.033.

62. Liu Y, Wang Z, Liu J, Levar C, Edwards MJ, Babauta JT, et al. A trans-outer membrane porin-cytochrome protein complex for extracellular electron transfer by Geobacter sulfurreducens PCA. Environ Microbiol Rep. 2014;6(6): 776-85. https://doi.org/10.1111/1758-2229.12204.

63. Shi L, Fredrickson JK, Zachara JM. Genomic analyses of bacterial porincytochrome gene clusters. Front Microbiol. 2014;5:657. https://doi.org/10.33 89/fmicb.2014.00657.

64. Leang C, Coppi MV, Lovley DR. OmcB, a c-type polyheme cytochrome, involved in Fe (III) reduction in Geobacter sulfurreducens. J Bacteriol. 2003; 185(7):2096-103. https://doi.org/10.1128/JB.185.7.2096-2103.2003.

65. Mehta T, Coppi MV, Childers SE, Lovley DR. Outer membrane c-type cytochromes required for Fe (III) and Mn (IV) oxide reduction in Geobacter sulfurreducens. Appl Environ Microbiol. 2005;71(12):8634-41. https://doi.org/1 0.1128/AEM.71.12.8634-8641.2005.

66. Alves A, Ly HK, Hildebrandt P, Louro RO, Millo D. Nature of the surfaceexposed cytochrome-electrode interactions in electroactive biofilms of Desulfuromonas acetoxidans. J Phys Chem B. 2015;119(25):7968-74. https:// doi.org/10.1021/acs.jpcb.5b03419.

67. Smith JA, Lovley DR, Tremblay PL. Outer cell surface components essential for Fe (III) oxide reduction by Geobacter metallireducens. Appl Environ Microbiol. 2013;79(3):901-7. https://doi.org/10.1128/AEM.02954-12.

68. Holmes DE, Chaudhuri SK, Nevin KP, Mehta T, Methé BA, Liu A, et al. Microarray and genetic analysis of electron transfer to electrodes in Geobacter sulfurreducens. Environ Microbiol. 2006;8(10):1805-15. https://doi. org/10.1111/j.1462-2920.2006.01065.X.

69. Leang C, Qian X, Mester T, Lovley DR. Alignment of the c-type cytochrome OmcS along pili of Geobacter sulfurreducens. Appl Environ Microbiol. 2010; 76(12):4080-4. https://doi.org/10.1128/AEM.00023-10.

70. Nevin KP, Kim BC, Glaven RH, Johnson JP, Woodward TL, Methé BA, et al. Anode biofilm transcriptomics reveals outer surface components essential for high density current production in Geobacter sulfurreducens fuel cells. PLoS One. 2009;4(5):e5628. https://doi.org/10.1371/journal.pone.0005628.

71. Smith JA, Tremblay PL, Shrestha PM, Snoeyenbos-West OL, Franks AE, Nevin KP, et al. Going wireless: Fe (III) oxide reduction without pili by Geobacter sulfurreducens strain JS-1. Appl Environ Microbiol. 2014;80(14):4331-40. https://doi.org/10.1128/AEM.01122-14.

72. Sun D, Wan X, Liu W, Xia X, Huang F, Wang A, et al. Characterization of the genome from: Geobacter anodireducens, a strain with enhanced current 
production in bioelectrochemical systems. RSC Adv. 2019;9(44):25890-9. https://doi.org/10.1039/C9RA02343G.

73. Inoue K, Ogura Y, Kawano Y, Hayashi T. Complete genome sequence of Geobacter sulfurreducens strain YM18, isolated from river sediment in Japan. Genome Announc. 2018;6(19):e00352-18. https://doi.org/10.1128/genomeA. 00352-18.

74. Röling WFM. The family Geobacteraceae. In: The Prokaryotes: Deltaproteobacteria and Epsilonproteobacteria. 2014. p. 157-72. https://doi. org/10.1007/978-3-642-39044-9_381.

75. Núñez C, Adams L, Childers S, Lovley DR. The RpoS sigma factor in the dissimilatory Fe (III)-reducing bacterium Geobacter sulfurreducens. J Bacteriol. 2004;186(16):5543-6. https://doi.org/10.1128/JB.186.16.5543-5546.2004.

76. Lin WC, Coppi MV, Lovley DR. Geobacter sulfurreducens can grow with oxygen as a terminal electron acceptor. Appl Environ Microbiol. 2004;70(4): 2525-8. https://doi.org/10.1128/AEM.70.4.2525-2528.2004.

77. Núñez C, Esteve-Núñez A, Giometti C, Tollaksen S, Khare T, Lin W, et al. DNA microarray and proteomic analyses of the RpoS regulon in Geobacter sulfurreducens. J Bacteriol. 2006;188(8):2792-800. https://doi.org/10.1128/JB.1 88.8.2792-2800.2006.

78. Aklujkar M, Young ND, Holmes D, Chavan M, Risso C, Kiss HE, et al. The genome of Geobacter bemidjiensis, exemplar for the subsurface clade of Geobacter species that predominate in Fe (III)-reducing subsurface environments. BMC Genomics. 2010;11(1):490. https://doi.org/10.1186/14 71-2164-11-490.

79. Preisig O, Zufferey R, Thöny-Meyer L, Appleby CA, Hennecke H. A highaffinity $\mathrm{Cb}_{3}$-type cytochrome oxidase terminates the symbiosis-specific respiratory chain of Bradyrhizobium japonicum. J Bacteriol. 1996;178(6):15328. https://doi.org/10.1128/jb.178.6.1532-1538.1996.

80. Hirai T, Osamura T, Ishii M, Arai H. Expression of multiple $\mathrm{cbb}_{3}$ cytochrome $\mathrm{c}$ oxidase isoforms by combinations of multiple isosubunits in Pseudomonas aeruginosa. Proc Natl Acad Sci U S A. 2016;113(45):12815-9. https://doi.org/1 0.1073/pnas.1613308113.

81. Mouser PJ, Holmes DE, Perpetua LA, DiDonato R, Postier B, Liu A, et al. Quantifying expression of Geobacter spp. oxidative stress genes in pure culture and during in situ uranium bioremediation. ISME J. 2009;3(4):454-65. https://doi.org/10.1038/ismej.2008.126.

82. Manzano-Marín A, Latorre A. Snapshots of a shrinking partner: genome reduction in Serratia symbiotica. Sci Rep. 2016;6(1):32590. https://doi.org/1 $0.1038 /$ srep32590

83. Hendry TA, Freed LL, Fader D, Fenolio D, Sutton TT, Lopez JV. Ongoing transposon-mediated genome reduction in the luminous bacterial symbionts of deep-sea ceratioid anglerfishes. MBio. 2018;9(3):e01033-18. https://doi.org/10.1128/mBio.01033-18.

84. Sharmin D, Guo Y, Nishizawa T, Ohshima S, Sato Y, Takashima Y, et al. Comparative genomic insights into endofungal lifestyles of two bacterial endosymbionts, Mycoavidus cysteinexigens and Burkholderia rhizoxinica. Microbes Environ. 2018;33(1):66-76. https://doi.org/10.1264/jsme2.ME17138.

85. Guo Y, Takashima Y, Sato Y, Narisawa K, Ohta H, Nishizawa T. Mycoavidus sp. B2-EB: comparative genomics reveals minimal genomic features required by cultivable Burkholderiaceae-related endofungal bacterium. Appl Environ Microbiol. 2020;86(18):e01018-20. https://doi.org/10.1128/AEM.01018-20.

86. Parkhill J, Sebaihia M, Preston A, Murphy LD, Thomson N, Harris DE, et al. Comparative analysis of the genome sequences of Bordetella pertussis, Bordetella parapertussis and Bordetella bronchiseptica. Nat Genet. 2003;35(1): 32-40. https://doi.org/10.1038/ng1227.

87. Preston A, Parkhill J, Maskell DJ. The Bordetellae: lessons from genomics. Nat Rev Microbiol. 2004;2(5):379-90. https://doi.org/10.1038/nrmicro886.

88. Brügger K, Torarinsson E, Redder P, Chen L, Garrett RA. Shuffling of Sulfolobus genomes by autonomous and non-autonomous mobile elements. In: Biochemical Society Transactions; 2004. p. 179-83. https://doi. org/10.1042/bst0320179

89. Filée J, Siguier $P$, Chandler M. Insertion sequence diversity in archaea. Microbiol Mol Biol Rev. 2007;71(1):121-57. https://doi.org/10.1128/MMBR. 00031-06.

90. Zhou F, Olman V, Xu Y. Insertion Sequences show diverse recent activities in cyanobacteria and archaea. BMC Genomics. 2008;9(1):36. https://doi.org/1 $0.1186 / 1471-2164-9-36$

91. Emms DM, Kelly S. OrthoFinder: phylogenetic orthology inference for comparative genomics. Genome Biol. 2019;20(1):238. https://doi.org/10.11 86/s13059-019-1832-y.
92. Katoh K, Standley DM. MAFFT multiple sequence alignment software version 7: improvements in performance and usability. Mol Biol Evol. 2013; 30(4):772-80. https://doi.org/10.1093/molbev/mst010.

93. Price MN, Dehal PS, Arkin AP. FastTree 2 - approximately maximumlikelihood trees for large alignments. PLoS One. 2010;5(3):e9490. https://doi. org/10.1371/journal.pone.0009490.

94. Aramaki T, Blanc-Mathieu R, Endo H, Ohkubo K, Kanehisa M, Goto S, et al. KofamKOALA: KEGG Ortholog assignment based on profile HMM and adaptive score threshold. Bioinformatics. 2020;36(7):2251-2. https://doi.org/1 0.1093/bioinformatics/btz859

95. Richter M, Rosselló-Móra R, Oliver Glöckner F, Peplies J. JSpeciesWS: a web server for prokaryotic species circumscription based on pairwise genome comparison. Bioinformatics. 2016;32(6):929-31. https://doi.org/10.1093/ bioinformatics/btv681.

96. Krzywinski M, Schein J, Birol I, Connors J, Gascoyne R, Horsman D, et al. Circos: An information aesthetic for comparative genomics. Genome Res. 2009;19(9):1639-45. https://doi.org/10.1101/gr.092759.109.

97. Siguier P, Perochon J, Lestrade L, Mahillon J, Chandler M. ISfinder: the reference Centre for bacterial insertion sequences. Nucleic Acids Res. 2006; 34(Database issue):D32-6 https://doi.org/10.1093/nar/gkj014.

98. Tatusova T, DiCuccio M, Badretdin A, Chetvernin V, Nawrocki EP, Zaslavsky L, et al. NCBI prokaryotic genome annotation pipeline. Nucleic Acids Res. 2016 44(14):6614-24. https://doi.org/10.1093/nar/gkw569.

\section{Publisher's Note}

Springer Nature remains neutral with regard to jurisdictional claims in published maps and institutional affiliations.
Ready to submit your research? Choose BMC and benefit from:

- fast, convenient online submission

- thorough peer review by experienced researchers in your field

- rapid publication on acceptance

- support for research data, including large and complex data types

- gold Open Access which fosters wider collaboration and increased citations

- maximum visibility for your research: over $100 \mathrm{M}$ website views per year

At $\mathrm{BMC}$, research is always in progress.

Learn more biomedcentral.com/submissions 